\title{
UNBUNDLING THE RETAIL GAS MARKET: CURRENT ACTIVITIES AND GUIDANCE FOR SERVING RESIDENTIAL AND SMALL CUSTOMERS
}

\author{
Kenneth W. Costello \\ Associate Director \\ for Gas and Electric Research \\ and \\ J. Rodney Lemon \\ Monmouth College

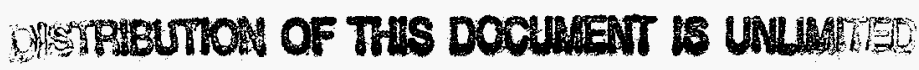

\author{
THE NATIONAL REGULATORY RESEARCH INSTITUTE \\ The Ohio State University \\ 1080 Carmack Road \\ Columbus, Ohio 43210
}

(614) 292-9404

7)

May 1996

This report was prepared by The National Regulatory Research Institute (NRRI) with funding provided by participating member commissions of the National Association of Regulatory Utility Commissioners (NARUC). The views and opinions of the authors do not necessarily state or reflect the views, opinions, or policies of the NRRI, the NARUC, or NARUC member commissions.

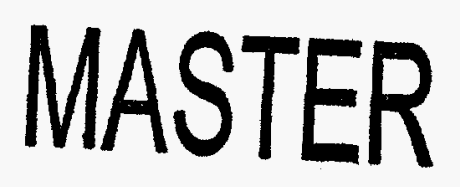




\section{DISCLAMMER}

Portions of this document may be illegible in electronic image products. Images are produced from the best available original document. 


\section{DISCLAIMER}

This report was prepared as an account of work sponsored by an agency of the United States Government. Neither the United States Government nor any agency thereof, nor any of their employees, make any warranty, express or implied, or assumes any legal liability or responsibility for the accuracy, completeness, or usefulness of any information, apparatus, product, or process disclosed, or represents that its use would not infringe privately owned rights. Reference herein to any specific commercial product, process, or service by trade name, trademark, manufacturer, or otherwise does not necessarily constitute or imply its endorsement, recommendation, or favoring by the United States Government or any agency thereof. The views and opinions of authors expressed herein do not necessarily state or reflect those of the United States Government or any agency thereof. 


\section{EXECUTIVE SUMMARY}

The restructuring of retail gas services has followed a typical pattern for previously heavily regulated industries: large customers are initially given rights to purchase unbundled services from different entities, with the same rights dispersed over time to smaller customers. For about ten years now industrial customers in most states have been able to "play the market." Since the passage of the Federal Energy Regulatory Commission (FERC) Order 636 in 1992, interest has centered on expanding service unbundling to small retail customers, including residential customers.

Importantly, the Order prohibited pipelines from providing bundled sales service. This is not surprising - in the telecommunications industry, for example, the unbundling of wholesale services was a strong stimulant for developing competition in the local exchange market.

The push for small-customer service unbundling has derived from the basic but politically attractive idea that all retail customers should directly benefit from competitive forces in the natural gas industry. When one looks at the movement of prices since 1985 , it is easy to see that large retail customers have enjoyed more favorable prices than other retail customers. For example, over the period 1985 to 1994 gas prices to industrial customers and electric utilities fell around 23 percent and 36 percent, respectively. In comparison, gas prices to residential customers increased by around 5 percent while gas prices to commercial customers decreased slightly by about 1 percent. $^{1}$

Service unbundling represents a major and expected feature of a competitive industry. The expansion of service unbundling to all retail customers will accelerate the evolution of competition in the natural gas industry. In this report, service unbundling

1 United States Department of Energy, Energy Information Administration, Month/y Energy Review (Washington, D.C.: Energy Information Administration, November 1995), 125. 
refers to the offering and pricing of individual gas services required by retail gas customers. These services can include gas procurement, transportation, storage, balancing, and billing.

Experiences in service and product unbundling across a spectrum of industries suggest three important lessons. First, unbundling should lead to lower prices without compromising service reliability. In the natural gas industry itself, evident by the unbundling of services by interstate pipelines and the unbundling of services to retail industrial customers, this has been shown to be true. Second, customers will avail themselves of unbundling opportunities. This outcome is not surprising since purchasing unbundled services or products or the repackaging of those services often times saves consumers large sums of dollars. Third, in spite of possible lost economies of scope, unbundling will likely benefit society at large. In addition to giving consumers more choices, unbundling also creates strong competitive pressures that elicit improved economic performance on the part of the firms in the industry. These firms tend to provide better price signals, increase utilization of existing physical assets, and engage in more innovations.

This report examines various dimensions of service unbundling to small retail gas customers, with special emphasis on residential customers. (The economic and policy issues surrounding service unbundling for small commercial customers and residential customers are fundamentally similar.) It identifies activities in states and Canadian provinces; reviews and evaluates the experiences in California and Ontario where residential programs have been in place for a number of years; discusses unbundling from a theoretical perspective; summarizes the "extreme" positions regarding residential service unbundling; discusses specific policy issues; and establishes guiding principles for executing residential service unbundling.

One major finding of this report is that the results from existing residential service unbundling programs have been encouraging. Experiences in California and Ontario have shown these programs can operate without creating reliability or other serious problems. One important lesson learned is that, to maximize the benefits to participating customers, regulators need to rid themselves of the "baggage" of heavy- 
handed regulation left over from the era when the natural gas industry was highly monopolistic.

The report points to the crucial role that state regulators will play in accommodating their rules and practices to an unbundled, competitive industry. Specifically, it advises the need for reforming existing regulation at its core. The operation of today's regulation was premised on a highly monopolistic, bundled-service natural gas industry. Since the industry no longer fits this description, regulatory reform becomes both economically and politically prudent. In the absence of reform, the net benefits of bundling become diminished, with possible net costs in the short term.

One principal outcome of regulatory reform should be to create a "level playing field" that would minimize the potential economic distortions from service unbundling. As illustrated by the experiences in Ontario, the debate over the necessary conditions for a level playing field will likely evolve over three issues. These issues are: (1) the separation of the LDC's distribution and merchant functions, (2) the LDC's need to offer multiple supply packages to fully compete with third-party merchants, and (3) the regulator's responsibility for determining whether the market for merchant service is contestable enough to allow for the deregulation of gas-procurement costs.

Skeptics and open opponents of residential service unbundling offer legitimate arguments and pose challenging questions that deserve a rejoinder from proponents. As the report argues, however, experiences across different industries and economic theory favor those who believe that extending unbundling to a greater number of customers and services would be beneficial to customers as a group and society at large.

Finally, the report establishes eight guiding principles applicable to residential service unbundling. These principles are based on three premises: (1) customers benefit when they have more choices, (2) risks should directly fall on the decisionmaker, and (3) all service providers should have equal opportunities to sell to residential customers or their agents. 



\section{TABLE OF CONTENTS}

Page

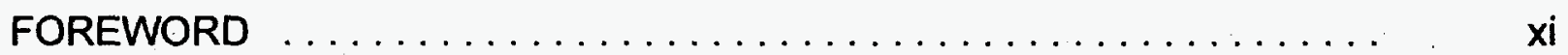

ACKNOWLEDGMENTS $\ldots \ldots \ldots \ldots \ldots \ldots \ldots \ldots \ldots \ldots \ldots \ldots \ldots \ldots \ldots \ldots$ xiii

CHAPTER

$1 \quad$ INTRODUCTION $\ldots \ldots \ldots \ldots \ldots \ldots \ldots \ldots \ldots \ldots \ldots \ldots \ldots \ldots$

2 State-Provincial Activities $\ldots \ldots \ldots \ldots \ldots \ldots \ldots \ldots \ldots$

3 Canadian Experience $\ldots \ldots \ldots \ldots \ldots \ldots \ldots \ldots \ldots \ldots$

Brief History . . . . . . . . . . . . . . . . . . . . 15

Experience On Residential Unbundled Service .......... 18

Conclusions On Lessons Learned $\ldots \ldots \ldots \ldots \ldots \ldots \ldots . \quad 28$

4 California Experience $\ldots \ldots \ldots \ldots \ldots \ldots \ldots \ldots \ldots \ldots$

The 1991 CAT Program . . . . . . . . . . . . . . . 31

Results Learned from the 1991 CAT Program . . . . . . . . 32

The 1995 CAT Program ..................... 33

Lessons Learned from California's CAT . . . . . . . . 37

5 Fundamental Economic Questions $\ldots \ldots \ldots \ldots \ldots \ldots \ldots$

Benefits from Residential Unbundling . . . . . . . . . . . . 41

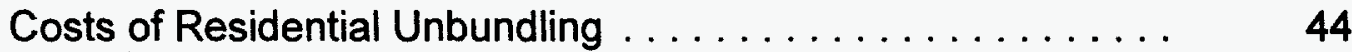

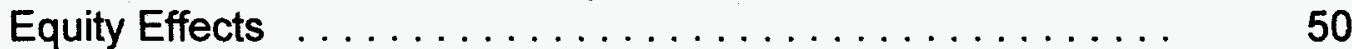

Have LDCs Gained from Bundled Service? ........... 55

Major Outcomes of Unbundling and Repackaging ........ 60

6 Opposing Positions $\ldots \ldots \ldots \ldots \ldots \ldots \ldots \ldots \ldots \ldots .67$

Skeptics of Residential Service Unbundling . . . . . . . . 67

Proponents of Residential Service Unbundling ........ 70 


\section{TABLE OF CONTENTS}

CHAPTER

7 Individual SPECIfic Policy Issues $\ldots \ldots \ldots \ldots \ldots \ldots \ldots$

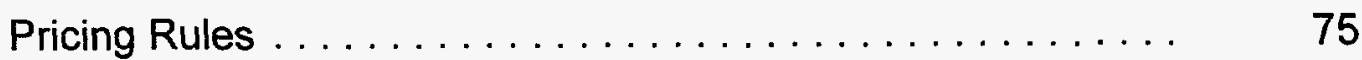

LDC Planning and Operation $\ldots \ldots \ldots \ldots \ldots \ldots \ldots \ldots . \ldots \ldots$

Funding Subsidized Services .................. 78

Comparability Conditions for Unbundled Residential Access . . $\quad 81$

Eligibility of Customers and Merchants . . . . . . . . . . 88

The Obligation To Serve ....................... 91

Allocation of Stranded Costs . . . . . . . . . . . . . . . 93

Marketers/Brokers and Unregulated Utility Affiliates ....... 97

8 Guiding Principles for Carrying OUt Residential

Service Unbundung . . . . . . . . . . . . . . . 103

9 Concluding Comments $\ldots \ldots \ldots \ldots \ldots \ldots \ldots \ldots \ldots$. 


\section{LIST OF TABLES}

2-1 Small-Customer SerVice Unbundling Activity by JuRISDiction $\ldots$.

3-1 Type of Gas Service to Ontario Gas Consumers $\ldots \ldots \ldots \ldots \ldots$

3-2 Provincial Residential Natural Gas Prices Relative to NATIONAL AVERAgES $\ldots \ldots \ldots \ldots \ldots \ldots \ldots \ldots \ldots \ldots \ldots$

5-1 Required Unbundled Services for Small Customers $\ldots \ldots \ldots \ldots .40$

5-2 Benefits Associated With Residential Service Unbundling . . . . . 42

5-3 Costs Associated With Residential Service Unbunduing $\ldots \ldots \ldots \quad 45$

5-4 Clarifying EXample: How Unbunding MaY LeAD to

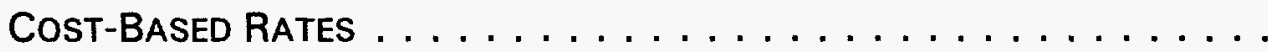

6-1 EnRon's Positions On Residential Service Unbundling $\ldots \ldots \ldots .72$

7-1 Specific Issues Surrounding Residential Service Unbundling $\ldots \ldots .74$

7-2 Comparability Needed for Residential Service Unbundling $\ldots \ldots .83$

7-3 Necessary Rules for Efficient Service $\ldots \ldots \ldots \ldots \ldots \ldots \ldots . \ldots 100$ 



\section{FOREWORD}

Service unbundling has become the major issue for state public utility commissions in the regulation of local gas distribution companies. Since the passage of FERC Order 636 in 1992, interest has shifted toward expanding service unbundling to small retail customers. Some states are beginning to address this subject, while others are expected to do so during the next several years.

This report examines the many policy and economic questions associated with small-customer service unbundling, with special emphasis on residential customers. It reviews the experiences of Canada and California, two jurisdictions that have had small-customer unbundling programs for the longest periods.

Douglas N. Jones, Director NRRI

Columbus, Ohio May 1996 



\section{ACKNOWLEDGMENTS}

The authors gratefully acknowledge the comments of Dr. Douglas $\mathrm{N}$. Jones of the NRRI, Mr. Dorman Davis of the Mississippi Public Service Commission, Mr. Terry Page of the Nevada Public Service Commission, and Mr. Calvin Timmerman of the Maryland Public Service Commission. The authors also appreciate the editing of Dr. Francine Sevel. Special thanks go to Ms. Marilyn Reiss for her always excellent secretarial and moral support, as well as the final proofread of this document. 


\section{CHAPTER 1}

\section{INTRODUCTION}

The evolution of competition in the U.S. natural gas industry has taken a predictable course. Wellhead deregulation stimulated pipeline restructuring, which in turn has provoked a debate over gas-service restructuring at the retail level. Over the last several years, almost all local gas distribution companies (LDCs) in the U.S. have had some kind of transportation program allowing industrial customers to purchase their gas supplies in the open market. By all accounts, service unbundling to large retail customers has achieved significant cost savings to these customers and a more economically efficient natural gas industry.

The current focus at the retail sector has gravitated toward small customers namely, small commercial and residential customers. Specifically, the current debate is over whether small customers should have the same right as large customers to purchase their gas supplies and other gas services from different providers. Increasingly, state public utility commissions (PUCs) are being asked to consider service unbundling to small customers. Although much of this activity is currently focusing on commercial customers, it is anticipated that a debate over service unbundling to residential customers will soon ensue.

To many observers, service unbundling to small customers, especially residential customers, is not as clear cut in terms of yielding economic benefits as it is to large customers. For example, they have questioned whether residential customers or their agents can procure gas supplies more cheaply than an LDC. They have also argued that the transaction cost for small customers, in terms of per-unit of gas purchased, may be much greater than for large customers. Finally, they believe the high cost of unreliable service to small customers may preclude reliance on market forces and contracts to assure these customers the high level of reliable service that they demand.

Taking everything into account, it cannot be said with certainty that service unbundling would benefit small customers or society at large. Although this statement 
may convey a message of caution to state commissions, it should not imply that service unbundling to small customers is inherently a bad idea. To the contrary, comprehensive service unbundling with the correct regulatory rules in place would further enhance competition in the natural gas industry. Service unbundling will ultimately be available to all retail customers. Although a debatable statement, many current skeptics of small-customer service unbundling see an inevitability to comprehensive retail gas-service unbundling.

This report will address several questions relating to residential gas-service unbundling. ${ }^{1}$ They cover a wide spectrum of economic and policy issues. The major ones include:

1. What positions and actions have regulatory bodies, both state PUCs and Canadian Provincial Boards, taken with respect to residential service unbundling?

2. For jurisdictions with unbundled residential services, how are the services unbundled and priced? How were specific issues addressed?

3. What have been the outcomes of residential service unbundling?

4. What lessons can be learned?

5. How would residential customers benefit from service unbundling?

6. What theoretical-analytical framework can be applied to evaluate residential service unbundling from the perspective of promoting standard regulatory objectives?

7. What are the major economic and policy issues associated with residential service unbundling?

8. How would the sphere and nature of state regulation change with residential service unbundling?

1 These questions, in almost all cases, equally apply to small commercial customers. A major reason for this is that, under unbundling, both groups of customers would require load aggregation and no daily metering. 
Although this report lacks definite answers to many of these questions, it attempts to advance the debate and advance and interpret initial evidence. It addresses fundamental economic and policy issues that most other documents fail to discuss or discuss only superficially. This report should complement the existing literature on residential gas-service unbundling. 



\section{CHAPTER 2}

\section{STATE-PROVINCIAL ACTIVITIES}

The expected expansion of service unbundling to more customers is now evolving. Although few states have executed unbundling for residential and small commercial customers, ${ }^{1}$ an increasing number have begun to recognize that broadbased unbundling warrants serious consideration.

A recently popular argument in favor of small-customer unbundling is that all retail gas customers should have the same opportunity to directly benefit from a more competitive natural gas industry. Several state commissions are beginning to ask the question: Why should only large customers have the right to choose among different gas suppliers? If the fruits of competition are to be enjoyed by all gas consumers, they reason, other customers in addition to large commercial and industrial ones should have the same opportunity to play the market. Of course, this requires the unbundling of different gas services. Commissions seem to be taking the position that several issues need to be addressed before small-customer unbundling should be executed on a large scale. Some of these issues were not explicitly discussed in the past debate over unbundling for large customers. ${ }^{2}$

Table 2-1 shows activities in several states, as of April 1, 1996, regarding residential and other small-customer unbundling. ${ }^{3}$ California was a leader in allowing small customers, including residential customers, to purchase gas from sellers other than the LDC. The original February 1991 California decision by the PUC approved of an experimental program. Since then the Core Aggregation Transportation (CAT)

1 Up to now, a common pattern has been for a state to initially consider residential service unbundling as a pilot or experimental program.

2 Two such issues are identifying the responsibilities and role of a load aggregator and the need for remote meters.

3 "Small customers" refer to residential and small commercial customers. 
TABLE 2-1

SMALL-CUSTOMER SERVICE UNBUNDLING ACTIVITY BY JURISDICTION

\begin{tabular}{|c|c|}
\hline Jurisdiction & Status \\
\hline California & Adoption of Permanent Core Aggregation Transportation (CAT) program \\
\hline Connecticut & $\begin{array}{l}\text { Requirement of firm transport service to commercial customers (Docket } \\
\text { No. 94-11-12) }\end{array}$ \\
\hline Georgia & $\begin{array}{l}\text { Notice of Inquiry investigation of procompetitive activities including } \\
\text { residential service unbundling }\end{array}$ \\
\hline Indiana & $\begin{array}{l}\text { Petition by Northern Indiana Public Service Company to allow gas- } \\
\text { supplier choice for all retail customers (Cause No. 40342) }\end{array}$ \\
\hline lowa & Rock Valley experiment \\
\hline Maryland & $\begin{array}{l}\text { Pilot programs for residential customers starting in Fall 1996; small- } \\
\text { commercial customer unbundling since } 1995\end{array}$ \\
\hline Michigan & Investigation of comprehensive service unbundling (Case No. U-11017) \\
\hline Minnesota & $\begin{array}{l}\text { Proposed small-customer program (excludes residential customers) } \\
\text { (Docket No. G-008/M-95-216) by Minnegasco }\end{array}$ \\
\hline New Hampshire & $\begin{array}{l}\text { Transportation for customers (individual or aggregated) who consume } \\
\text { more than } 10,000 \text { therms for any one month }\end{array}$ \\
\hline New Jersey & Requirement of firm transport service to commercial customers \\
\hline New York & Requirement of core (commercial and residential) aggregation programs \\
\hline Ohio & $\begin{array}{l}\text { Proposed experimental transportation service for residential customers } \\
\text { (Cincinnati Gas and Electric) } \\
\text { Experimental transportation service for small customers (East Ohio Gas) } \\
\text { LDCs pressured by PUC to conduct pilot residential programs within the } \\
\text { next two years }\end{array}$ \\
\hline Pennsylvania & $\begin{array}{l}\text { Proposed pilot residential program by Equitable Resources } \\
\text { Formation of Global Issues Committee to study issues relating to small- } \\
\text { customer unbundling }\end{array}$ \\
\hline Washington & $\begin{array}{l}\text { Notice of Inquiry investigation of procompetitive policies (Docket No. UG- } \\
940778 \text { ) }\end{array}$ \\
\hline
\end{tabular}


TABLE 2-1

SMALL-CUSTOMER SERVICE UNBUNDLING ACTIVITY BY JURISDICTION - Continued

\begin{tabular}{|l|l|}
\hline \multicolumn{1}{|c|}{ Jurisdiction } & \multicolumn{1}{|c|}{ Status } \\
\hline Wyoming & $\begin{array}{l}\text { White Paper recommended opportunities for load aggregation of all } \\
\text { customers } \\
\text { Adoption of KN Energy's "Choice Gas Service" program }\end{array}$ \\
\hline $\begin{array}{l}\text { Alberta, British Columbia, } \\
\text { Manitoba, Ontario, Quebec, } \\
\text { Saskatchewan }\end{array}$ & Direct gas sales to core (commercial and residential) customers \\
\hline \\
Source: Various sources, 1995-1996. See footnotes in this chapter.
\end{tabular}

program has become a permanent fixture. ${ }^{4}$ The California PUC has modified the program to protect nonparticipating customers and to minimize stranded costs. In a July 1995 order, the California PUC gave small customers more opportunities to benefit from service unbundling. ${ }^{5}$

The California Commission allowed customers to choose among different transportation providers. This starts in 1998 for Pacific Gas and Electric and 1999 for Southern California Gas and San Diego Gas and Electric. These customers or their agents (for example, marketers) will have the opportunity to purchase interstate pipeline capacity in competitive markets. The California PUC estimated that small customers

${ }^{4}$ A detailed discussion of the California program is presented in Chapter 4.

${ }^{5}$ See Miriam Swydan, "Significant State Commission Actions Regarding Unbundling and Deregulation of Local Distribution Company Services," Gas Energy Review (December 1995), 3; and Reed Consulting Group, Highlights and Summaries of Core Aggregation Pilot Programs and Services Offered by LDCs in North America and Great Britain (Lexington, MA: Reed Consulting Group, February 1996), 4-6. A major part of the Commission decision is the requirement that the large LDCs in the state unbundle their interstate transportation service and tariffs from the CAT service. 
were paying, on average, about 70 percent more than large or noncore customers for interstate pipeline capacity because of their inability to take advantage of competitive opportunities in interstate transportation markets. ${ }^{6}$ The Commission rejected unbundled rates for core services such as meter reading, billing, and collections. Results from the California program are discussed further in Chapter 4.

Last year the lowa Public Utilities Board approved a one-year residential unbundling program for the town of Rock Valley, starting on November 1, 1995. ${ }^{7}$ During the open season that ran last September about 83 percent of eligible residents signed up for the program. ${ }^{8}$ Three different marketers were chosen to supply gas to the city gate. During public sessions with the residents, the marketers offered their services at guaranteed savings. ${ }^{9}$ The LDC, MidAmerican Energy, will provide transport, billing, and metering services. MidAmerican Energy will act as the backup supplier and will continue to supply bundled sales service to those choosing to not participate in the program.

The lowa Utilities Board identified several issues that should be addressed if the program is to become permanent. These issues include tax discrepancies, the status of the winter moratorium, the service obligation of the LDC, the need for telemetering, the risks to an LDC, actual cost savings to customers, and gas supply imbalances. ${ }^{10}$ So far a conspicuous outcome of the program is that residential customers, if given the choice, would seem to prefer choice as much as large customers. One interpretation of this outcome is that all customers presumably have strong incentives to reduce their

${ }^{6}$ Conversation with California PUC staff in January 1996.

7 A description of the Rock Valley experiment is contained in Nancy S. Boyd, "The Role of Market Intermediaries in the Natural Gas Industry," presented at the 27th Annual Conference of the Institute of Public Utilities at Michigan State University, Williamsburg, Virginia, December 12, 1995; and Beverly Wharton, "State Unbundling Experiments," presented to the NARUC Committee on Gas, Washington, D.C. February 27, 1996.

${ }^{8}$ Seventy-five percent of the customers signed up with one marketer, Equitable Gas-Energy.

9 One marketer, for example, guaranteed annual savings of $\$ 75$; another marketer guaranteed 10 percent annual gas savings plus no-cost appliance service repair.

10 See Boyd, "The Role of Market Intermediaries in the Natural Gas Industry," 9. 
gas bills. At least in this limited case, residential service unbundling has passed the market test. The Rock Valley experiment may, however, not be reflective of future programs where the LDC assumes less risk and the customers assume more risk. MidAmerican Energy has assumed a large role in guaranteeing service reliability to participating customers. ${ }^{11}$

Last year, Equitable Resources proposed a two-year experimental program, starting in April 1996, that would allow commercial and residential customers in the Borough of Pleasant Hills, Pennsylvania to choose among different natural gas and electricity suppliers. ${ }^{12}$ At the time of this writing, the proposal is under review by the Pennsylvania PUC. Pennsylvania has also organized a Global Issues Committee, comprised of PUC staff and different interest groups, to study various issues surrounding small-customer unbundling. ${ }^{13}$ These issues include tax reform, service obligations, gas supply reliability, and social welfare responsibilities.

In Minnesota, Minnegasco has proposed firm transportation service for small customers. ${ }^{14}$ Residential customers, at least for the foreseeable future, would be excluded from the service. The intent of Minnegasco is to give a wider array of customers the opportunity to take advantage of firm transportation service while, at the same time, allowing it to recover any resultant transition costs. As part of Minnegasco's proposal, customers could procure their own firm interstate transportation capacity as long as Minnegasco could remarket or turn back to its pipelines capacity previously

${ }^{11}$ One marketer, Equitable Gas-Energy, has complained that the program requires marketers to take the upstream pipeline capacity of MidAmerican (which is costlier than alternative capacity) and to serve all customers who opted for unbundled service. See Gregory Martin, "State Unbundling Experiments," presented to the NARUC Committee on Gas, Washington, D.C., February 27, 1996.

${ }^{12}$ See "Equitable Gas Requests Local Open Access Projects for Gas and Electricity in Pennsylvania Similar to Rock Valley, lowa Natural Gas Experiment in Which Equitable is Participating," Foster Report No. 2055 (November 9, 1995): 18-19; and Reed Consulting Group, Highlights and Summaries of Core Aggregation Pilot Programs and Services Offered by LDCs in North America and Great Britain, 10. Corporation.

${ }^{13}$ Conversations with Laura Murrell of Tenneco Energy and Timothy Merrill of Direct Gas Services

${ }^{14}$ See Minnegasco's Petition for Approval of a Miscellaneous Rate Change to Revise Its Tariffs in Response to Industry Changes Brought About by FERC Order 636, filed before the Minnesota Public Utilities Commission, April 14, 1995. 
purchased to meet these customers' sales-service demands. Minnegasco would also require transportation customers to absorb a portion of the transition costs associated with Federal Energy Regulatory Commission (FERC) Order 636. Customers eligible for the transportation service would be allowed to aggregate their load with other customers. Minnegasco proposed a three-year experimental program for the aggregation of small commercial and industrial customers by gas marketers or brokers. ${ }^{15}$

Public utility regulators in Connecticut and New Jersey have approved of transportation programs for small commercial customers. ${ }^{16}$ Residential customers were excluded, presumably because of the lack of pressure placed on the regulators to allow these customers to choose their gas suppliers. These regulators may have also believed that issues unique to residential unbundling should be addressed separately and at a later time. In fact, the New Jersey Board is currently contemplating extending service unbundling opportunities to residential customers. One LDC, South Jersey, is developing a residential experimental program that is expected to be proposed later this year to the Board of Public Utilities. ${ }^{17}$

Two states, Maryland and New York, will have residential transportation programs by the 1996-1997 heating season. The staff of the Maryland PUC recommended that experimental programs be instituted by the state's largest LDCs by November $1996 .{ }^{18}$ It is expected that a complete evaluation of these programs will not occur before $1998 .{ }^{19}$ In the New York Policy Proceedings, the Commission ordered that

\footnotetext{
${ }^{15}$ Highlights of the proposal are contained in Swydan, "Significant State Commission Actions Regarding Unbundling and Deregulation of Local Distribution Company Services," 3.

${ }^{16}$ Ibid., 3; and American Gas Association, "Providing Unbundled Services To Small Volume Customers: Issues to Consider in the Implementation Process," Policy and Analysis Issues (January 5 , 1996), 3-4, 7, 9, 11-19.

${ }^{17}$ Reed Consulting Group, "Supplier Choice for Residential Customers," presented to the NARUC Committee on Gas, Washington, D.C., February 27, 1996.

${ }^{18}$ Calvin Timmerman, "Maryland Gas LDC Unbundling Roundtables: Past, Present and Future," presented to the NARUC Subcommittee on Gas, Washington, D.C., February 28, 1996. Last year, the Maryland Public Service Commission approved of small-commercial unbundling programs.

${ }^{19}$ Ibid., 9.
} 
load aggregation of residential and small customers be allowed. ${ }^{20}$ These customers will be required to purchase backup service. The Commission hopes to approve of smallcustomer unbundling service programs for each of the state's LDCs by early $1996 .{ }^{21}$

The programs will have the following guidelines. ${ }^{22}$ First, during the three-year transition period customers must take assignment of an LDC's upstream capacity at the utility's average cost. Second, rates for aggregated services will be at the tariff levels less all upstream costs, with the utilities prohibited from imposing administrative fees for new services. Third, nonregulated marketing affiliates are permitted to serve in related companies' territories provided they abide by Affiliated Company Standards. Fourth, utilities are prohibited from streamlining gas to an on-system customer unless other customers would be worse off without the transaction, that is, physical or alternative fuel bypass would otherwise occur. Fifth, imbalance trading between customers of a single aggregator or multiple aggregators or customers on the same pipeline, if prearranged by customers or marketers, is allowed. Utilities are expected to provide flexibility permitting balancing of accounts between service classifications. Finally, the New York Department of Public Service staff will monitor customer satisfaction with regard to the performance of marketers and LDCs in informing the public of the new services available.

\footnotetext{
${ }^{20}$ New York Public Service Commission, Restructuring of the Emerging Competitive Natural Gas Market, Opinion No. 94-26, issued December 20, 1994 and Order on Reconsideration, issued August 11, 1995. In the latter, the Commission established guidelines for load aggregation proposals. It should be noted that, unlike Maryland, New York plans to initiate unbundling programs for residential and commercial customers at the same time.

${ }^{21}$ Conversation with John Zekoll of the New York Public Service Commission in December 1995. All the major gas distributors in the state have filed tariff-sheet proposals in compliance with the Order on Reconsideration. The Commission's response to the proposals is contained in New York Public Service Commission, Proceeding on Motion of the Commission to Address Issues Associated with the Restructuring of the Emerging Competitive Natural Gas Market, Case 93-G-0932 et al., March 28, 1996. In the Order, the Commission approved compliance filings for eight LDCs.

${ }^{22}$ John Zekoll, "New York/Maryland Unbundling: Compare and Contrast," comments presented at the Fifth Annual DOE-NARUC Natural Gas Conference, St. Louis, Missouri, May 1, 1996.
} 
In a White Paper, the Wyoming PSC agrees in principle that all customers should be allowed "to form aggregations of their own to seek commodity suppliers." ${ }^{23}$ In February of this year, the Commission approved of a comprehensive service unbundling plan by KN Energy. The plan, labeled the "Choice Gas Service" program, would allow residential and commercial customers in ten communities to choose their natural gas provider. The program, which begins in June of this year, will be reviewed by the Commission after one year of operation. Initially, customers who choose another gas supplier will continue to receive upstream pipeline services from KN Energy. ${ }^{24}$

The Ohio PUC has strongly supported the principle that transportation service should be offered to all customers. It has encouraged LDCs to file transportation tariffs for small customers. In November 1994, a settlement agreement approved by the Commission provided for an experimental small-customer transportation service that would include residential customers. ${ }^{25}$ In a current rate case filing, Cincinnati Gas and Electric has proposed a transportation service for residential customers. ${ }^{26}$

The Michigan PSC (U-11017) ordered formal hearings, beginning in February 1996, to investigate transportation service for all gas customers. ${ }^{27}$ The Commission

${ }^{23}$ See Wyoming Public Service Commission, "The Development of a Competitive Model for the Future of Retail Natural Gas Services and Regulation in Wyoming," Commission White Paper (November 1, 1995):

A truly competitive market should be able to bring [gas supply] options and choices to our smaller commercial and even residential customers. . . Marketers should have the opportunity to aggregate customers and provide commodity supplies to the distribution utility for delivery to those end-use customers. Customers should also be able to form aggregations of their own to seek commodity supplies (p. 10).

${ }^{24}$ For a discussion of the KN Energy program, see Steve Ellenbecker, "State Unbundling Experiments," presented to the NARUC Committee on Gas, Washington, D.C., February 27, 1996; and "Wyoming PSC Approves KN Energy's 'Choice Gas Service," Foster Report No. 2068 (February 22, 1996): 20.

${ }^{25}$ The settlement involved East Ohio Gas Company. The experiment would include up to 500 customers, including residential customers who consume less than 300 million cubic feet (Mcf) of gas per year.

${ }^{26}$ Case No. 95-656-6A-AIR.

27 "Michigan PSC will Begin Formal Examination of Open Access Natural Gas Transportation Issues on February 12," Foster Report No. 2064 (January 25, 1996): 36. 
hopes the investigation will encompass a benefit-cost analysis of broad-based service unbundling. Areas of investigation identified by the Commission include: (1) existing barriers to gas transportation service, (2) rate designs required for broad-based transportation service, (3) the economic implications of small-customer service unbundling, (4) the costs associated with expanding gas transportation service, and (5) a timeframe for expanding gas transportation, if found appropriate. ${ }^{28}$

In November 1995, Northern Indiana Public Service proposed what it calls the Gas Alternative Regulatory Plan. ${ }^{29}$ The plan includes service unbundling for all gas customers.

In December 1995, the Georgia PSC issued a Notice of Inquiry that will investigate actions that the PSC could take to enhance competition in the retail gas sector. ${ }^{30}$ The investigation, pending at the time of this writing, has included discussion on residential service unbundling. Marketers favor service unbundling for all customers. ${ }^{31}$ The state's largest LDC, Atlanta Gas Light, proposes a limited pilot program for new residential and commercial customers.

Pursuant to a 1993 commission order, New Hampshire transportation service has been available to customers, individual or aggregated, who consume more than 10,000 therms for any one month. Up to now residential customers have shown no interest in the service. The biggest barrier has been the requirement that each customer purchase a remote meter. $^{32}$

28 Ibid.

${ }^{29}$ Petition of Northern Indiana Public Service Company for Approval of a Natural Gas Alternative Regulatory Plan Pursuant To Ind. Code 8-1-25-1, Et Seq. and Experimental Effectiveness of New Gas Rate 330, Large Volume Negotiated Sales Service, filed before the Indiana Utility Regulatory Commission, Cause No. 40342, November 28, 1995.

${ }^{30}$ Georgia Public Service Commission, Notice of Inquiry on Transition to Increasing Natural Gas Competition, November 21, 1995.

${ }^{31}$ These marketers include Enron Capital and Trade Resources and Tenneco Energy.

${ }^{32}$ Conversation with staff personnel of New Hampshire Public Utilities Commission. 
As of the time of this writing, residential experimental programs are being developed by LDCs in Massachusetts (Bay State Gas) and Wisconsin (Wisconsin Gas). These programs are expected to be proposed for implementation by the fall of $1996 .^{33}$

Outside the United States, several Canadian provinces have allowed direct gas sales to residential customers. ${ }^{34}$ Some of these arrangements, in the form of buy/sell transactions, have been in place for several years. ${ }^{35}$. For example, since 1987 the Ontario Energy Board has allowed direct gas purchases by residential customers. A full discussion of the problems faced, issues addressed, and actual performance of these arrangements follows in Chapter 3 . One point to make here is that the Canadian experience has shown that residential service unbundling can work if properly designed. Canadian provinces have had varying successes with their residential unbundling programs. For example, in Ontario about 250,000 residential customers currently receive their gas requirements through a buy/sell alternative. Some of the Canadian provinces have made changes to their residential unbundling rules in response to specific problems and new developments.

${ }^{33}$ See Reed Consulting Group, "Supplier Choice for Residential Customers."

${ }^{34}$ A discussion of these activities is contained in "Direct Gas Sales to Core Market Consumers in Alberta," Canadian Natural Gas Focus (May 1995): 2-8.

${ }^{35}$ In a buy/sell transaction, gas purchasers contract with gas producers or brokers who sell gas to the gas distributor at an agreed-upon price. The gas distributor, in turn, delivers the gas to the retail customer. 


\section{CHAPTER 3}

\section{CANADIAN EXPERIENCE}

While several state regulatory commissions have approved of experimental or full residential access programs, residential access has been feasible in some Canadian provinces for a decade. The Canadian programs are examined for insight into resolutions of commonly perceived problems and problems not necessarily pondered. ${ }^{1}$ Also the nature of the benefits realized from such regulatory policy are measured.

\section{Brief History}

Canadian deregulation began in 1985 with a series of intergovernmental accords The Western Accord on Energy Pricing and Taxation on March 28, 1985, and The Agreement on Natural Gas Markets and Prices (The Halloween Agreement) signed by the governments of Canada and various provinces on October 31, 1985:

The agreement among participating governments is intended to create the conditions for a new marketresponsive pricing system. ...it signals a return to market forces characterized by choices for buyers and sellers. . . The new regime will provide the framework for negotiated prices between buyers and sellers. Prices will be affected by conditions in the marketplace; both supply and demand will influence price. Competition will be fostered which should increase the industry's ability to react quickly to changing conditions.

1 The Canadian institutional environment is not entirely parallel to the United States. The extent of competition among pipelines is considerably less. TransCanada possesses a near total monopoly in many regions, and pipeline utilization rate is higher. The result is higher rates in the secondary market. The 1985 agreements also permitted distributors some ability to ratchet down their wellhead contracts as customers shifted to direct purchase. 
At the distribution level, issues arose such as the unbundling of rates, bypass, and allocation of benefits and costs among the various consumer groups and those leaving or remaining as utility customers. In the provinces of Ontario, Manitoba, and Quebec provisions were created for immediate access for unbundled residential service. ${ }^{2}$ In British Columbia, a more incremental development of unbundled residential access has transpired. Because Ontario represents the least constrained and British Columbia the most constrained programs on unbundled residential access, these programs are the focus of this section.

The Ontario Energy Board (OEB) in a 1987 decision determined that the deregulation movement should be implemented through opening access and unbundling services that constitute delivered natural gas to all customers. Ontario's direct purchase market for residential customers was essentially free to operate without oversight from government regulators. Aggregators/brokers/merchants (ABMs) could use buy/sells or any other alternative in arranging transmission capacity. ${ }^{3}$ Significant savings were initially gained because spot wellhead prices were low compared to the price of the utility's portfolio of long-term fixed-price supply; also some ABMs made use of lower cost, short-term contracts for transmission capacity and storage. This lower cost lasted until turbulence developed in 1993 when spot-wellhead prices rose above

${ }^{2}$ Manitoba was the first province to implement rules providing residential access, and Quebec initiated its program at the same time as Ontario. Manitoba's rules for unbundling residential service are similar to those in Ontario. The results also have parallels: the gas distributor in Manitoba is Centra whose corporate parent also owns Union Gas in Ontario; the current percentage of residential customers using direct purchases is similar in each service area.

Rules providing residential choice for alternative direct purchaser's access in Quebec are more constraining and are more reflective of rules in British Columbia. Quebec's rulemakings may reflect the greater possibility of transmission bottlenecks that the regulator must guard against or may reflect the fact that the government has a major ownership interest in the gas utility. Hence, residential access is more politicized, and the potential for stranded costs is a greater concern for the regulator.

${ }^{3} \mathrm{~A}$ buy/sell arrangement is a means of procuring gas supply whereby ownership of the gas is transferred from the seller to the LDC for delivery to end users. The LDC normally bills the buy-sell customer at its tariffed rate for system gas. The seller rebates to the customer the difference in price between the gas distributor's WACOG and the gas purchased on behalf of the customer, after subtracting for an agent fee. 
the utility's weighted average cost of gas (WACOG). As a consequence, some ABMs withdrew and shifted their customers back to the utility for service. ${ }^{4}$ The OEB held hearings followed by a Code of Conduct for all merchants proposed by the Ontario Natural Gas Association, and a Code of Ethics drawn up by the Direct Purchase Industry Committee (DPIC). Currently, the OEB is in the midst of a new inquiry that could result in the separation of the utility's merchant function from its distribution function. The utilities have focused on the advantages of offering menus with multiple supply portfolios for which the OEB would show lighter price regulatory oversight while remaining both merchant and distributor. ${ }^{5}$

On the other hand, the British Columbia Utility Commission (BCUC) initial Inland Transportation decision in 1987 and its Core Market Policy in 1988 sought unbundled access for only large industrial customers. ${ }^{6}$ Over time, the unbundled service option was expanded to residential customers with various restrictions. Thus, the experiences of these two provinces present not only experiences with different policies, different timing, and some different market characteristics, but also some convergence over time.

${ }^{4}$ Paul Woods of Ontario-Wide stated at the OEB's recent hearings that less than one-half of one percent of all customers left their direct purchase service through this period of high spot-wellhead gas prices. Robert Callow of Municipal Gas Corporation claimed that no customer has been denied service or been financially disadvantaged by taking direct purchase service in Ontario. Yet, others argue that a large number of customers were shifted back to the utility's merchant service and that the utility's WACOG was forced up because of incremental purchases to serve these customers.

5 The OEB's recent hearings carried the official headings "Where We Are" and "Where Should We Be Going." The hearings were a review of a decade of experience and an examination of the current market structure.

6 The BCUC stated that unbundled service should be limited to those customers who were "knowledgeable." While the intent for this was to limit access to large users, some argued that a residential customer indicated knowledge when a contract was signed with an ABM. Hence, residential access should be provided. The BCUC changed its language to state that the customer should have alternative fuel capability to gain unbundled access. In 1992 this requirement was dropped and the BCUC focused on constraints on ABMs. 


\section{Experience On Residential Unbundled Service}

Residential access can be judged as a success in that no party is arguing before the OEB or the BCUC that their regulation should return to the preaccess era. Further, residential access programs are still expanding as an area of regulatory interest in Canada. For example, an inquiry that could dramatically increase the competitive pressures (decrease regulation) on the merchant function of the utility and the ABMs that serve residential customers is underway in the province of Manitoba. ${ }^{7}$ Residential unbundling is also being studied in Alberta.

The specific experience with residential access can be approached from two levels. First, what are the data on the number of customers who have made use of this alternative; what has been the impact upon their price and quality of service and the price of service for those remaining with the utility? Second, what changes have the regulators undertaken to resolve problems or to facilitate greater gains as they and the industry participants learned more from operating under the actual programs? ${ }^{8}$

7 The number of residential customers taking service from an ABM likewise has increased over time and is currently around 13 percent of all residential customers. While there were one or two ABMs who handed their residential customers back to the utility during the period of high spot prices in 1993, this presented no problem at the time, as only around 2 percent of all residential customers were making use of ABMs and only a small number of these withdrew. The stronger ABMs continued service throughout this turbulence and have grown greatly since.

On June 10,1996, the Manitoba Public Utilities Board (MPUB) has invited parties to present evidence and comments on a series of questions on how the MPUB regulates the utility's merchant function and the prices for unbundled services. This list includes:

4. If the minimum level of service [by the utility] does not include natural gas procurement, transportation or storage, please discuss separation issues related to existing contracts, security of supply, obligation to serve, backstopping, nominations and load balancing.

7. Please discuss the guidelines for acceptable conduct between Centra Gas Manitoba Inc. and affiliated companies, including the methodology and costing for the transfer of assets, the sharing of resources including human resources and the use of a common name.

8 The regulatory pressure in Canada for performance-based rates with regard to the distributor's gas contracting costs is totally absent. Instead, utilities are seeking greater flexibility in their pricing given that customers have other choices. This alternative focus may be viewed as one success of the OEB's policy. 
The success of residential unbundled service can be judged by cost savings or the number of participating households. This participation is dependent upon (1) the time period in which access was instituted (disequilibrium in the utility's rates compared to competitive rates), (2) whether there were barriers to entry, such as high administrative charges and constraints on the options available to the ABMs, and (3) the services (commodity, transmission, storage) upon which savings can be based. Success can also be judged by simply providing greater choice. By this standard, success becomes a tautology with the development of unbundling.

\section{Empirical Measures on Unbundled Residential Access}

Two tables are presented which give some indication of the benefits achieved by Ontario's residential-unbundling program. Information on the number of residential customers who have self-selected this option is shown in Table 3-1. An indication of the lower prices for all residential customers is presented in Table 3-2.

Currently, the share of residential gas volumes in Ontario making use of ABMs for gas, transportation, and storage procurement ranges from 9 percent within the service area of Union Gas to 34 percent within the service area of Consumers Gas (see Table 3-1). In service areas other than that of Union Gas, the number of residential customers taking merchant service from $A B M s$ has steadily increased over time and the number of ABMs are fewer today than in the early 1990 s.

Table 3-2 shows published natural gas prices, relative to the national residential price, for those residential customers choosing service from their utilities. Provincial changes in regulations may affect the local prices and, hence, become more or less attractive relative to other provinces and the national average. The data indicate that residential prices have become relatively lower in provinces that instituted unbundled residential service. These data ignore rebates that residential customers may have received from direct purchase merchants. Thus, the observed trend is likely more pronounced than shown in the published data. 


\begin{tabular}{|c|c|c|c|c|c|}
\hline \multicolumn{6}{|c|}{$\begin{array}{l}\text { TABLE 3-1 } \\
\text { TYPE OF GAS SERVICE TO ONTARIO GAS CONSUMERS }\end{array}$} \\
\hline & & \multicolumn{2}{|c|}{ Direct Purchase } & \multicolumn{2}{|c|}{ Utility Supply } \\
\hline $\begin{array}{l}\text { Customer } \\
\text { Segment }\end{array}$ & Utility & $\begin{array}{l}\text { By Number of } \\
\text { Customers } \\
(\%)\end{array}$ & $\begin{array}{c}\text { By Volume } \\
(\%)\end{array}$ & $\begin{array}{l}\text { By Number of } \\
\text { Customers } \\
(\%)\end{array}$ & $\begin{array}{l}\text { By Volume } \\
(\%)\end{array}$ \\
\hline Residential & $\begin{array}{l}\text { Centra } \\
\text { Consumers Gas } \\
\text { Union }\end{array}$ & $\begin{array}{l}25 \\
30 \\
12\end{array}$ & $\begin{array}{r}33 \\
34 \\
9\end{array}$ & $\begin{array}{l}75 \\
70 \\
88\end{array}$ & $\begin{array}{l}67 \\
66 \\
91\end{array}$ \\
\hline Commercial & $\begin{array}{l}\text { Centra } \\
\text { Consumers Gas } \\
\text { Union }\end{array}$ & $\begin{array}{r}6 \\
36 \\
18\end{array}$ & $\begin{array}{l}55 \\
75 \\
42\end{array}$ & $\begin{array}{l}94 \\
64 \\
82 \\
\end{array}$ & $\begin{array}{l}45 \\
25 \\
58\end{array}$ \\
\hline Industrial & $\begin{array}{l}\text { Centra } \\
\text { Consumers Gas } \\
\text { Union } \\
\quad<70010^{3} \mathrm{~m}^{3} \\
>70010^{3} \mathrm{~m}^{3}\end{array}$ & $\begin{array}{l}33 \\
52 \\
25 \\
87\end{array}$ & $\begin{array}{l}80 \\
91 \\
44 \\
95\end{array}$ & $\begin{array}{l}67 \\
48 \\
75 \\
13\end{array}$ & $\begin{array}{r}20 \\
9 \\
56 \\
5\end{array}$ \\
\hline \multirow[t]{2}{*}{ Total } & $\begin{array}{l}\text { Centra } \\
\text { Consumers Gas } \\
\text { Union }\end{array}$ & $\begin{array}{l}26 \\
31 \\
15\end{array}$ & $\begin{array}{l}77 \\
65 \\
65\end{array}$ & $\begin{array}{l}74 \\
69 \\
85\end{array}$ & $\begin{array}{l}23 \\
35 \\
35\end{array}$ \\
\hline & Total & 25 & 67 & 75 & 33 \\
\hline $\begin{array}{r}\text { Source: } \mathrm{Ce} \\
\text { the }\end{array}$ & $\begin{array}{l}\text { nsumers Gas, a } \\
\text { Natural Gas Co }\end{array}$ & $\begin{array}{l}\text { ion, "Joint Uti } \\
\text { lity in Ontario" }\end{array}$ & $\begin{array}{l}\text { osition } \mathrm{Pa} \\
\text { cember } 19\end{array}$ & $\begin{array}{l}\text { on the Market } \\
7 .\end{array}$ & ture for \\
\hline
\end{tabular}


TABLE 3-2

PROVINCIAL RESIDENTIAL NATURAL GAS PRICES RELATIVE TO NATIONAL AVERAGES

\begin{tabular}{|l|c|c|c|c|c|}
\hline Year & Ontario & Saskatchewan & $\begin{array}{c}\text { British } \\
\text { Columbia }\end{array}$ & Manitoba & Alberta \\
\hline 1985 & $118.8 \%$ & $78.6 \%$ & $93.9 \%$ & $97.6 \%$ & $72.4 \%$ \\
\hline 1986 & $115.8 \%$ & $77.4 \%$ & $95.2 \%$ & $98.3 \%$ & $70.4 \%$ \\
\hline 1987 & $116.1 \%$ & $75.9 \%$ & $95.0 \%$ & $99.8 \%$ & $86.0 \%$ \\
\hline 1988 & $115.7 \%$ & $80.8 \%$ & $95.8 \%$ & $89.8 \%$ & $67.2 \%$ \\
\hline 1989 & $112.4 \%$ & $83.0 \%$ & $105.0 \%$ & $95.8 \%$ & $69.3 \%$ \\
\hline 1990 & $111.1 \%$ & $86.7 \%$ & $102.7 \%$ & $104.9 \%$ & $68.8 \%$ \\
\hline 1991 & $112.3 \%$ & $87.3 \%$ & $98.2 \%$ & $94.0 \%$ & $74.3 \%$ \\
\hline 1992 & $110.8 \%$ & $85.4 \%$ & $102.4 \%$ & $101.7 \%$ & $68.1 \%$ \\
\hline 1993 & $109.0 \%$ & $86.4 \%$ & $100.0 \%$ & $107.0 \%$ & $73.5 \%$ \\
\hline 1994 & $108.7 \%$ & $86.8 \%$ & $99.4 \%$ & $106.5 \%$ & $74.5 \%$ \\
\hline
\end{tabular}

Source: Energy, Mines and Resources, Statistics Canada and Canadian Gas Price Reporter. 
On the other hand, the hypothesis that prices should have risen more in 1993 and then fallen more in 1994 and 1995 does not appear to hold because a higher portion of the contracts are market sensitive. ${ }^{9}$ This expected price pattern may have been hidden when variances between the projected and actual WACOGs were collected. Further, many customers in Ontario experienced higher costs in 1993 versus 1992 through the absence of a rebate check from their direct purchase merchant.

\section{Evolution of Unbundled Residential-Access Regulation}

Numerous facets and conflicting opinions surround the issues related to unbundled residential access. A flavor of these issues and their resolution in Canada follows. These issues are discussed under five categories, namely, (1) maintaining reliability, (2) pricing of unbundled service, (3) achieving cost-effective operations, (4) separating the merchant function from the utility's distribution function, and (5) lessening regulatory control over prices and the menu of choice offered by the utility's merchant service.

\section{How Is Reliability Achieved? How Has This Resolution Evolved?}

While the reliability issue was raised in the OEB's initial hearing, the OEB essentially disregarded handringing and adopted the "recourse service" perspective. The OEB's regulation provided customers a regulated, reliable, bundled, delivered natural gas service. If customers wished to make an alternative choice, this decision was theirs, and the OEB did not need to exercise stringent regulatory oversight. The OEB would mitigate any upward cost impact upon the utility's remaining customers caused by the exit or return of the customers who shifted to direct purchase. Reliability

9 Contrary to common belief, interviews with several ABMs revealed that they are contracting for some of their supplies on a long-term basis. They have been willing to take a position to lock in what they perceived as favorable prices. Thus, the perfect correlation between greater unbundling of services and more flexible pricing may not always hold. 
associated with unbundled access was left to ABMs and their customers for determination. This finding was fully consistent with the spirit of the 1985 agreements. ${ }^{10}$

The OEB's review in 1993 was concerned with whether some tightening of oversight of the ABMs was necessary. The OEB largely deferred to the industry to resolve this issue. The Ontario Natural Gas Association developed a Code of Conduct, which would have all merchants (ABMs and utilities) agree to adhere to city-gate supply standards, such as providing a three-year rolling gas supply and a three-year firm transportation with firm deliverability up to 110 percent of daily volume. The Direct Purchase Industry Committee set forth a Code of Ethics specifying various customermerchant contract relations such as a minimum notice period before a customer can change supplier, a minimum duration that the customer must remain with a merchant, ethical salesmanship and standardized disclosure statements. These Code-of-Ethics terms can now be observed in industry practices. The OEB's current separation inquiry may result in greater emphasis on creating conditions for lighter regulatory oversight.

On the other hand, in 1991 the BCUC promulgated tight regulatory rules over how ABMs could contract for residential unbundled services. ABMs in British Columbia must use pipeline capacity gained through the utility's buy/sell, must have long-term commodity contracts, and must make use of the utility's bundled distribution service. The BCUC's review both in 1993 and 1995 revealed that long-term commodity contracts did not convey any greater reliability, but because of perceived transmission bottlenecks, the one-for-one use of buy/sells from the utility has not varied.

This comparison indicates some convergence among the two provinces, but the regulatory philosophy in Ontario remains more market driven than in British Columbia. The shift of customers back to the utility's system supply in Ontario in 1993 presented neither a capacity nor commodity reliability crises; rather, the issue was whether the

${ }^{10}$ Because capacity is so fully utilized on TransCanada, the ABMs largely made use of transmission capacity the utility already had under contract (buy/sells), lessening the emergence of stranded costs and mitigating the reliability issue. A few ABMs may have made use of spot purchasing of transmission capacity, but this was not a major activity. Further, there was some queue for new firm capacity on TransCanada. With respect to commodity contracts, the 1985 governmental agreements had permitted these to be unilaterally reduced if the market evaporates. Thus, no exit costs were charged to the remaining core customers. 
utility experienced an increase in its commodity price because of new purchases at a time of higher wellhead prices. This price and potential cost-shifting issue turned out to be minimal when compared to the price increases experienced in other provinces. The BCUC had great fears at the outset but far fewer fears today.

In provinces in which demand may exceed pipeline capacity, regulators have devised specific rules granting $A B M s$ and reclaiming access from $A B M s$ as their customer usage changes. Buy/sell arrangements not only eased administrative costs but they also maintained tight control over service reliability. In provinces where alternative pipelines, access to market hubs, and storage exist, and transmission capacity is less fully utilized, regulators have shown less concern for how reliability is attained.

\section{How Are Residential Unbundled Services Priced?}

Residential customers have experienced the same monthly bill whether purchases are from the utility's bundled package or the ABM's portfolio. ${ }^{11}$ The latter simply has the potential for a rebate computed over some multimonth period. Residential bills in both Ontario and British Columbia contain prices based on the utility's current projected WACOG adjusted for the difference between prior projected and actual incurred costs. This pricing is consistent with the ABM delivering its supply portfolio to the utility and being paid the utility's WACOG. The WACOG becomes a straight passthrough.

When the utility's supply portfolio was made up of long-term, fixed-price contracts, some of which had become commercially impractical, the ABM could enter and easily predict success in offering firm service at a lower price. Today, this is less obvious - some observers say it is convoluted. The residential customer (or the ABM

11 The distributor currently charges the ABM a $\$ 6$ per customer fee per year plus a monthly fee per aggregator pool. The $\$ 6$ customer fee is down from the $\$ 40$ fee charged to customers to change suppliers when unbundling commenced in 1988. The ABM/residential sharing and any fee arrangement are deregulated and not subject to a reporting requirement. These add-on charges have not been significant barriers to entry. They can be contrasted to metering plus administrative charges to commercial customers that, in some states, amounted to up to $\$ 230$ per month. 
for that matter) when making a purchase decision cannot easily know whether the final price of either the utility's or the ABM's supply portfolio will generate a positive rebate (that is, a price for gas purchased on behalf of a customer that is less than the gas distributor's WACOG). The utility is currently purchasing the commodity with prices indexed to a variety of market sensitive indicators. Arguably, the utility's prices are closer to marginal costs but the short-term variance between projected and actual costs can be significant and not easily predictable. No one observes the costs of the components the ABM experiences.

One argument often cited in favor of unbundling is the emergence of more accurate prices. The shift to indexed commodity prices is the only apparent realization of this dimension; but this shift away from long-term, fixed-price contracts is observed in all provinces though possibly not to the same extent as in the provinces with unbundled residential access. With choice, the utility price indexing must be more responsive to competitive levels and to price swings. ${ }^{12}$

Basing pipeline capacity contracting entirely upon use of buy/sell arrangements likely restricts achieving lower-cost service. In Ontario, third-party merchants have been able to gain their own storage, make portfolio decisions, use market hubs, and access pipeline capacity in the United States.

In British Columbia, the potential for an ABM to achieve lower residential prices through unbundling rests solely with commodity contracting. The savings on commodity contracting would also need to exceed the administrative access fee that residential customers pay to use an $A B M$. Because of this combination, no ABM has been successful in entering the residential market. Greater unbundling of a utility's services or greater freedom in pipeline contracting also would likely improve the responsiveness of the $A B M s$ to buy/sell transactions.

${ }^{12}$ While price-indexed contracts have gained widespread usage, some contractual terms include premiums above the relevant spot or city-gate market price. Customer choice may best regulate what the relevant premiums are. 


\section{How Are Operational Costs Minimized?}

The OEB's decision in 1987 was noteworthy in keeping the residential access program simple and unencumbered. To some extent, the OEB recognized that administrative costs were lower with firm residential access than with interruptible industrial access. ABMs were simply required to deliver on terms parallel to how a utility arranges its aggregated pool of residential customers based on its estimated maximum daily quantity (MDQ). Penalties associated with imbalances, nominations, and so forth exist but are less burdensome than what is typically observed in the United States. The fact that customers are billed by the utility at its WACOG also lessens operational costs. The costs associated with customers shifting among merchants have been minimized through a standard coded format to the utility's specification that is delivered on disk or electronically.

The Code of Ethics developed standards with respect to the frequency and notice period for changing suppliers. These rules lessen the likelihood of costs being passed on to the "stable" customers. The DPIC's solution has been to require twelvemonth merchant contracts, a waiting period to return, and a possible entry period. Thus, with this Code of Ethics the industry participants have developed operation rules that achieve the OEB's policy of not raising rates to existing customers because of other customers swinging among merchants.

The OEB did not initially require an ABM to be bonded. This potentially could have presented a problem, but has not. The ease of other ABMs to assume additional customers was clearly demonstrated. ${ }^{13}$ Because the stranded cost exposure of the $A B M$ is quite small, the bonding requirement if compulsatory, should not be a barrier to entry for $A B M s$.

One of the OEB's first concerns with the development of residential unbundling was mimimizing operational costs. Maintaining the utility in its traditional role of

\footnotetext{
${ }^{13}$ It is perhaps the regulatory cultural mindset that presumes that other merchants will not want to serve additional customers. Rather with competition, we observe companies (for example, MCI/ATT/ Sprint) offering to pay new customer hook-up charges plus cash bonuses to gain customers from their competitors.
} 
providing a bundled package priced at the WACOG eased the administration of gas flows and billing. Yet, this regulatory strategy in addition to lessening disruption and risks also disadvantages the utility (because of less freedom in services provided and continued regulatory oversight of prices) relative to the ABM. Because of this, new regulatory action aimed at achieving a level playing field may be warranted. If the playing field is level, the utility as merchant gains the ability to offer multiple supply portfolios and the ABMs gain "competition" opportunities based on more equal access. Hence, with the comfort factor established that residential customers do value choice, that the distribution system can function with residential choice and third-party merchants, that lower net costs can be experienced, the regulatory oversight that is considered optimum would continue to evolve. The next two issues before the OEB reflect this transition.

\section{How Can the Playing Field Be Leveled?}

Both competing merchants and several consumer groups posit that the current regulatory environment is tilted in favor of the utility. The utility is both a supplier and gatekeeper. While the utilities were helpful in the period 1989 to 1992, after the turbulance in 1993 some utilities may have more aggressively sought to discourage shifts to direct purchases. ${ }^{14}$

Even Consumers Gas, which all ABMs credited as being a fair utility, was preceived to tilt the playing field through (1) unclear information in customers' bills, (2) biased wording in customer surveys, (3) no education program, (4) buy/sells, and (5) control of gas purchase agreements that limit multiyear relations.

The debate within the province on what factors constitute a level playing field shifted in 1993 back to the initial issues of reliability and the cost of backup service.

${ }^{14}$ Comments by the Institutional Gas Users Association and by the Ottawa-Carleton and London Gas Purchase Consortia. The latter stated at the hearings that "several years ago, the utilities ceased being facilitators and became competitors in the commodity market." 
Once disequilibrium was over and the utilities had made adjustments to their WACOG that were more reflective of contracts that were commercially feasible, outperforming the WACOG became more difficult.

In the recent OEB hearings, several stakeholders argued that the utility allocates costs such that the utility's merchant service becomes cross-subsidized by its distribution service. This creates market distortions. Only through enforcement of strict affiliate separation rules can this cross-subsidization be mitigated. Once separation is achieved, the OEB could end WACOG pricing of gas procurement costs. Alternatively, separation of the merchant function from the utility's distribution service would permit market pricing of gas procurement costs, which would be reflective of the merchant's marginal costs. The level playing field, thus, permits a better choice of services and more accurate prices.

The level playing field in Ontario is a critical issue because (1) alternatives exist on how the utility or ABMs should contract, (2) competition among merchants could reveal the way to contract, and (3) too many supply options exist for the regulator to make a prudence determination. In British Columbia, although there are pipeline capacity constraints, it is dubious whether the perceived bottleneck crisis over the supply of last resort should limit contracting options to the extent the BCUC has constrained choice. Procedurally, achieving a level playing field will involve several stages of hearings. The first stage will focus on whether unbundling is a good idea. Then the focus will shift toward creating a level playing field on which more customers can participate. Finally, the focus will evolve to a discussion of whether some form of divesture and separation between the distribution and merchant functions of the utility should follow.

\section{Conclusions on Lessons Learned}

The regulatory response to residential service unbundling has been a function of

(1) the regulator's own learning curve in becoming comfortable with residential access,

(2) the extent to which pipeline utilization limits choice and creates bottlenecks, and 
(3) as prices are permitted to play a larger role, the severing of the linkage between long-term contracts and service reliability. Currently in 1996, the discussion in Ontario has progressed to allowing the utility to offer a menu of services and leveling the playing field among the utility and the ABMs. These pragmatic issues are subject to empirical determinations. In the past, the major philosophical issue was whether the utility and only the utility could provide reliable service to customers who made small use of natural gas.

Additional lessons can be learned. First, choice should be valued as a regulatory goal in and of itself. Second, lower prices are likely to result from unbundling residential services. Third, unless the distributors are relieved of tight regulatory control, they are likely to suffer financially in a hybrid regulated-competitive environment. Regulatory liberalization should entail creating a level playing field. Fourth, compared to the United States, Canada more appropriately treats administrative costs and transaction costs. Canada imposes no additional metering charges. Experience indicates that providing unbundled residential access is not really that difficult. Finally, the merchant function is contestable at the residential level. As competition resolves major gaps among merchants, with consequences in practices and prices, regulators are pressured to remove barriers that continue to hamper competitive forces. These pressures characterize the current arguments of ABMs in Ontario. On the other hand, increased competition and convergence increase the search for product differentiation and "niche" competition. 


\section{CHAPTER 4}

\section{CALIFORNIA EXPERIENCE}

Starting in 1986, the California Public Utilities Commission (CPUC) has taken incremental steps in providing customers with competitive opportunities. This process started with the CPUC differentiating customers as either being core or noncore and providing the option of unbundled services to the noncore. ${ }^{1}$ In February 1991, the CPUC set forth rules on an experimental transportation-only service for core gas customers who aggregate their loads. This policy was viewed as a further step in the evolution toward more open and competitive gas markets by offering small and medium-size core customers their first opportunity to participate. Most recently, the CPUC has reviewed and issued a major broadening of unbundled access for core customers to commence in 1998 and 1999 . This chapter reviews this evolution, the results and lessons learned.

\section{The 1991 CAT Program}

The initial core aggregation transportation (CAT) program had the following characteristics. First, customer participation was limited to 10 percent of total volume and to a total of ten aggregators. Second, customers could split their gas procurement. That is, customers could have part of the gas contracted from the utility and part from a third-party merchant, but the distribution utility's gas would be considered first through the meter. Third, the customer's third-party merchant was granted pro rata access to the distributor's interstate pipeline and storage entitlements, paying the same rates as contained in the distributor's contractual obligations. This provision limited the

1 The distinction largely rested upon whether the customers had alternative fuel capability. Core customers then included principally residential and commercial customers and industrial customers with small gas usage. 
emergence of stranded costs and permitted access even when capacity bottlenecks existed; on the negative side, it constrained the opportunity for more efficient contracting of upstream gas services.

Fourth, the CPUC did not require the third-party merchant to purchase Canadian supplies as it did the distributor, even though the distributor had specific contractual agreements on these purchases. The CPUC found that the utility dominance in gas procurement markets could undermine the development of more competition. Fifth, balancing and standby provisions placed the core firm customer served by third-party merchants above noncore customers if curtailment is required. Sixth, the CPUC developed a core balancing fee of $\$ 10$ per decatherm for backup service but permitted aggregators to trade imbalances among themselves to minimize this charge. The imbalance penalties would be assigned to marketers and not directly to core customers.

Seventh, the CPUC made sure that the "undercollected" balance account associated with the utility's bundled sales service did not become the motive for customers to switch away from the distributor, and that the current "overcollected" balance account did not become the motive for core customers to return to bundled sales service. Lastly, if there were increased administrative costs arising from core unbundled service, in the distributor's next rate case the CPUC would develop a new account to capture and charge these costs.

\section{Results Learned from the 1991 CAT Program}

As discussed earlier in this chapter, alternative approaches exist to judge whether a program is successful. One approach evaluates whether intervening parties are seeking to return, to add new regulatory contraints, or to lessen regulatory oversight. Another approach would examine customer participation and relative changes in gas prices compared to similarly situated core customers for whom core aggregation was not possible. Using the first criteria, the CPUC reviews performed in 1994-95 revealed a Commission willingness to broaden the appeal and make more components of the former bundled sales service part of the unbundling program. 
Particularly noteworthy is the CPUC's new willingness to modify or eliminate the distinction between core and noncore customers. These latter changes suggest that the 1991 experimental program was a success.

With regard to the second approach of judging the success of the 1991 CAT program, some reduction in gas costs for the participating core customers likely resulted. However, its appeal has declined as indicated by the number of customers, volumes, and the number of participating core aggregators. On the Pacific Gas and Electric system, the number of core aggregators initially rose to ten, serving 8 percent of the core market. Today, there are only three aggregators serving 4 percent of the total core market. Participation within the Southern California Gas franchise area has fallen from 5.3 percent of core load to 3.6 percent in 1995 . Yet, this trend may also be a sign of program success. Namely, competition in core markets may have motivated the utilities to improve their gas procurement practices. Also with the amount of excess pipeline capacity, some core customers may have converted to noncore status; this conversion does not imply that the 1991 CAT program was not an improvement over the previous bundled-sales-service regime. The CPUC states that the administration of this program has generally been successful, even though questions exist over whether some rules may have granted undue customer protection and added costs to the utility.

\section{The 1995 CAT Program}

The experimental CAT program was reviewed in 1994 and extended with minor modifications pending a more in-depth review. In July 1995, the Commission announced significant modifications. In reaching its conclusion, the Commission explicitly noted two alternative paths that were identified. Both paths were feasible but the CPUC explicitly found that the path that would increase the competitive options and promote more opportunities for core customers was the superior course relative to simply calibrating again the administrative rules of the prior program that had shown limited appeal. 
The CPUC noted that any residential unbundling program should (1) promote efficient use of the gas system, (2) provide core customers with service options to the extent feasible, (3) assure that core customers continue to receive the highest quality service (although the CPUC notes that some core customers may wish to select lower quality service and should have this option), and (4) assure fair allocation of costs between customers and customer classes.

The evolution of the characteristics of the revised core aggregation program reveals a general finding that the direction of this evolution is desirable and fewer regulatory constraints are necessary. A discussion of selected new characteristics follows.

\section{Unbundling Rates and Services}

Additional unbundling of core services is now regarded as the correct policy. The CPUC refers to separating interstate transportation, storage, and customer service costs from core rates. ${ }^{2}$ This additional unbundling poses two major issues: how are stranded costs handled?; and can core customers be allowed to select their own quality of service? These issues are treated below in some detail.

\section{Stranded Costs}

Currently, California has excess pipeline capacity to serve the in-state market for natural gas. Distributors have multiyear contracts providing entitlement to firm capacity that require large annual fixed payments irrespective of throughput. Quasi-firm capacity can be purchased by third-party merchants at a fraction of the full maximum tariff: the distributor's firm entitlement to pipeline capacity under contract is currently 70 percent

${ }^{2}$ Customer service fees cover a wide range of services such as energy conservation and usage information, billing and payment policies; meter reading, safety inspections, and carrying costs for storage gas. 
higher than the price for firm capacity purchased on the secondary market. If the CPUC permitted core customers to contract directly or through their aggregators for pipeline capacity, large stranded costs would emerge. The CPUC would have to determine who would pay these costs. During the CPUC's review, noncore customers sought assurances that these stranded costs would not be included in their rates (even though the stranded costs that arose when they exited were paid in part by increasing core rates). The CPUC arguably finessed this by delaying implementation of new rules until the distributors' major transmission contracts come up for renewal in 1997 or 1998. This permits the distributors to contract at more market-based rates with more flexible terms that would reduce stranded costs. Core-customer rates could arguably remain above competitive levels in the interim, however.

The CPUC considered whether noncore customers should be charged some of the transitional costs. The Commission noted that in the past each time improved competitive options were provided to noncore customers or reduced noncore rates were approved, core customers shared in the associated stranded costs. So the question can be asked, Why should noncore customers not share in the stranded costs caused by core customers? The CPUC has promoted competition as a regulatory philosophy on the basis that competition will promote efficiency and drive down prices. Unbundling for core customers is likely to generate similar efficiencies for which noncore customers may benefit, but even if they do not, unbundling core transportation will most likely improve allocative efficiency. Distribution utilities will be discouraged from maintaining high-priced firm capacity contracts that are not needed to reliably serve utility customers in circumstances of excess capacity.

\section{Core/Noncore Distinction}

The CPUC acknowledges that unbundling rates and services effectively eliminates most remaining distinctions between core and noncore customers. The distinction will depend only on who serves the customer (whether residential or industrial) - the distribution utility or competing suppliers for gas, storage, and transportation. The CPUC's definition of the core class and the options available to 
core customers have thus changed as circumstances have varied. Core customers may not require the utility to act on their behalf as long as those customers are willing to assume risks. ${ }^{3}$ Further, all core customers should not be required to purchase the same level of utility service.

\section{Obligation to Serve}

A result of unbundling core service is the explicit acknowledgment that unbundling restricts the distribution utility's obligation to the provision of high reliability within the distributor's service area. While the distribution utilities claimed that this . change would decrease the integrity of service, the CPUC placed greater weight upon the core customers' right to self-select their level of service. Distributors argued that assuring backup services to these core transportation customers would be costly and should not be assumed by other customers. Utilities also provide various "after meter public safety services that should not be circumvented.

\section{Degree of Unbundling}

Brokerage costs should be unbundled and separately priced. The CPUC directed distributors to submit a cost-of-service study based upon their marginal cost of core procurement. The CPUC decided not to unbundle storage at this time because storage is being used to assure reliability, not to facilitate purchase of low-priced gas. Based on this reasoning, the CPUC determined that unbundling should not be extended to storage.

3 The CPUC refers to the possibility that customers may select lower levels of interstate transportation service. With options of competing providers and with price playing a more pronounced role in allocating transmission and storage capacity, lower levels of quality may not be the determining factor in customer selections. 


\section{Lessons Learned from California's CAT}

The following five general conclusions can be deduced from the core customer aggregation program in California:

1. Unbundling has a disciplining effect upon a distributor's behavior that leads to better cost service.

2. Unbundling can lessen inequalities that otherwise arise when access is granted to one class of customers and not others.

3. Many of the fears surrounding the provision of service options to core customers are unfounded.

4. As state regulation restricts the parameters that can be optimized by a thirdparty merchant - for example, only gas commodity procurement - the amount of participation in the program will decrease over time, as the distributor adjusts its own procurement.

5. The issue of stranded costs is real but can be mitigated by specific commission policies. 



\section{CHAPTER 5}

\section{FUNDAMENTAL ECONOMIC QUESTIONS}

Good public policy demands that the benefits of any action exceed the costs. Measuring these parameters is never easy, especially when viewed from a long-term perspective. For example, service unbundling inevitably increases competition in the natural gas industry. To the extent that economic efficiency improves, the benefits may remain invisible for a number of years. In the meantime, by ignoring or highly discounting these benefits, service unbundling looks less attractive. Similarly, somé costs associated with service unbundling may be overlooked. One possible cost is lost economies of scope or coordination when individual gas services are provided by different entities.

In any event, the benefit-cost model represents the appropriate conceptual framework to evaluate the aggregate net effect of service unbundling. It looks at public policy from the perspective of economic efficiency. As such, the benefit-cost model does not take into consideration the distributional effects and the short-term political response. Since many of the parameters are not immeasurable, the benefit-cost framework should be viewed as no more than a guide to decisionmaking. Its attractiveness lies in the ability of one to think about the desirability of a policy by enumerating and, to the extent possible, quantifying the different effects that the policy is expected to have.

In its simplest form, service unbundling involves the separation of a particular service currently offered to consumers into individual components. In the case of retail gas, bundled sales service comprises several subservices or components (see, for example, Table 5-1). They include, among other services, distribution, pipeline transportation, storage, gas procurement, metering and billing, and balancing. Under pure unbundling, each of these subservices would be offered and priced separately. Subservices could also be combined into a single rebundled package. Rebundling to 
TABLE 5-1

REQUIRED UNBUNDLED SERVICES FOR SMALL CUSTOMERS

- Gas procurement

- Pipeline transportation

- Interstate storage

- Nominations and balancing on pipeline

- Load projections and nominations

- On-system peaking

- On-system balancing

- On-system storage

- Distribution

- Metering

- Accounting and billing

Source: Laura L. Murrell, "Workable Unbundling To Provide Competitive Alternatives for All LDC Gas Customers," presented at the Great Lakes Conference of Public Utility Commissioners, Sulfur Springs, West Virginia, July 11, 1995. 
foster one-stop shopping commonly occurs in many industries. In the future natural gas industry, LDCs and other entities could play the role of rebundler by aggregating various services into a package that is sold at a market-based price.

A striking example of unbundling occurs with respect to computer hardware and software. A customer has numerous choices. At one extreme she can purchase a personal computer system with all of her hardware and software requirements packaged together. At the other extreme, she can purchase each component of the computer hardware - for example the chip, modem, monitor, mouse, and keyboard as well as individual software programs. She can assemble the hardware components and install the programs herself or pay someone else to do it. In between these two options, she could purchase any combination of bundled hardware or software components. For example, she may want a packaged hardware system but may prefer to purchase the software separately.

Myriad examples exist in nonregulated markets where consumers have choices between various combinations of bundled and unbundled services or products. How consumers choose among these combinations depends on such factors as transaction costs, the demand characteristics of consumers, and the degree of product or service interdependency.

\section{Benefits from Residential Unbundling}

Table 5-2 lists the potential benefits from the unbundling of residential gas services. These benefits, which can be significant to society as a whole, include the following.

1. Consumer preferences are better met. Different customers have different preferences for price risk, least-cost service, quality of service, the freedom to choose, and so forth; producers' preferences also differ among themselves. When the distributor provides only one basic supply service, the terms and conditions underlying the distributor's portfolio may differ from what many 
TABLE 5-2

BENEFITS ASSOCIATED WITH

RESIDENTIAL SERVICE UNBUNDLING

- Better price signals

- Lower regulatory costs

- Better principal-agent dealings

- Improved regulation

- Services better matched to consumer preferences

- Gains to all gas consumers from more competitive natural gas industry

- Better utilization of natural gas

- More efficient industry investments

consumers most prefer and also may leave many producers without the terms by which they gain greater value. Only free and total interchange of gas services will provide each party the ability to achieve maximum welfare. This simply cannot be met by the LDC's contracting decisions that are approved by the state regulator. 
2. Unbundled residential access resolves the contract portfolio issue.

Regulatory rules can interfere with gas producers and consumers gaining the contract duration or price stability that they seek. Access gives each producer a larger number of parties with which to contract and, hence, the ability to negotiate the terms most preferred. Likewise, access gives each consumer a larger number of producers with which to contract and, hence, the ability to negotiate more favorable terms. Access removes any bias that LDCs or regulators can exert that would cause contracts to differ from that determined by market forces.

3. Unbundled residential access resolves any principal-agent divergence. The regulated firm may face regulatory guidelines that contain few rewards for superior behavior but contain penalties for inferior performance. In this situation, the gas distributor may seek to minimize its exposure to risk rather than aggressively searching for the "best cost" service. For example, some state regulators have limited distributor's incentives to use financial market derivatives by allocating gains to ratepayers and allocating losses to shareholders. State regulatory agencies are not well equipped to judge sophisticated purchasing strategies; only market pressures can accomplish this satisfactorily.

4. The scope of state regulatory oversight is diminished. ${ }^{1}$ The state regulator no longer needs to judge the terms and conditions for the purchase or sale of (1) gas commodity, (2) transmission capacity, (3) storage, or (4) supplemental peaking supplies. It is also no longer necessary to include those factors in the LDC's regulated rates. The market is too dynamic and is not well-suited for improved traditional or performance-based regulation. Thus, not only are

1 At the federal level, nondiscriminatory access has enabled the FERC to end its oversight of prices paid for wellhead gas supplies and, in certain circumstances, its oversight over the price and conditions for storage services. At the state level even more substantial lessening of the regulatory oversight is feasible. Areas for the termination of state PUC oversight include gas costs via the purchased gas adjustment clause (PGA), costs of pipeline contracting, and local peaking supplies. 
regulatory costs reduced but market-determined decisions result in more accurate price signals to consumers, distributors, and producers.

5. Cost shifting among customer classes is minimized. When unbundled residential access is denied to some customers, it is possible to bifurcate the market. This may permit costs to be unduly shifted to one or more customer groups. Wellhead to burner-tip access would diminish this ability to shift costs and, hence, would lessen inequality among customer classes.

6. Dynamic forces for improving regulation are created. Unbundled residential access resolves not only the principal-agent problem associated with which portfolio of services should be contracted, but access also affects the specific changes sought in the regulatory-legislative arena. At the federal level, the distributor's role becomes augmented by unregulated marketers. These marketers' profits are tied directly to serving customers best. As these marketers become more dominant, their presence will tend to alter the regulatory environment toward workably competitive markets.

\section{Costs of Residential Unbundling}

There is considerable divergence of opinion on the costs to serve residential customers through unbundled services. Some observers of the industry perceive that high costs will limit the viability of this option. ${ }^{2}$ Still others note the absence of merchants clamoring for this option. On the other hand, the higher costs incurred to serve residential customers may provide greater opportunity and challenges for new merchants. Some state PUCs may believe that the market can provide this answer; yet, unless regulators take a proactive stand in creating a fair basis on which all service providers could effectively enter and compete, the market may malfunction.

Several comparisons may be at issue. Plainly, the third-party merchants may have higher costs in providing residential service than in providing industrial service.

${ }^{2}$ See, for example, the discussion in Chapter 6. 
These higher costs in maintaining service for low load-factor customers, however, already exist for the distributor in providing this service. The question is whether a third-party merchant would have lower or higher costs than comparable service provided by the distributor. The following discussion identifies five cost components (see Table 5-3).

TABLE 5-3

COSTS ASSOCIATED WITH RESIDENTIAL SERVICE UNBUNDLING

- Incremental billing activities

- Monitoring of physical-system integrity

- Stranded costs

- Low load-factor costs

- System planning costs

\section{Billing Costs}

The issue here is whether new costs associated with billing customers for their gas usage arise once residential customers use the distributor for only transmission from the city gate to the burner tip. Until now, many customers selecting unbundled transportation from the distributor have been required to pay additional charges for 
time-of-use meters and, in some instances, for a dedicated telephone line. ${ }^{3}$ These additional billing charges have made unbundled service uneconomical to customers with smaller usage.

The elements to billing costs include (1) the type of meter required and its reading, (2) the cost of changing a customer's account from one merchant to another, and (3) the cost of determining each customer's historical monthly gas requirements, and the cost of aggregating these requirements by merchant to obtain each merchant's monthly required deliveries. ${ }^{4}$

The calculation of monthly nominations by a residential customer is more difficult than calling the energy manager of a large industrial firm who has analyzed the firm's energy usage in detail. Yet, once the residential customer's usage is calculated (distributors have models that make these projections), residential nominations have small variations. On the other hand, the industrial firm's demand hinges upon economic activity and specific industry, firm, and product characteristics that not even the industrial firm always predicts well.

The additional billing costs of a residential customer choosing unbundled service is quite small. The information on the customer's selection can be electronically transmitted by the new merchant to the distributor. The distributor must perform a onetime electronic check against the customer's past usage pattern, and have a computer program that inserts the merchant's name and prices when printing the traditional monthly bill.

${ }^{3}$ Often, these customers are large commercial and industrial end users. The charges have been defended as compensation for monitoring whether customer's usage during capacity-constrained periods is diminished if a customer takes interruptible service or whether customer's peak-day usage lies within the bounds of the nomination entitlement.

4 The determination of whether existing residential customers who take service from a particular third-party merchant have a different load pattern than other residential customers and, hence, should be charged differently should not be considered as a cost of unbundling or access. Plainly, differences in load patterns among these residential customers have been ignored in establishing prior rates. 
A merchant serving customers in a new residential subdivision would rely upon the same monthly projected gas usage that the distributor currently projects if it was providing the merchant service. There is no new cost in making this determination. Likewise, the distributor currently bills and reads the meter. In addition, other activities would not need to change under unbundling unless the commission wishes to expand the range of unbundled services.

How incremental costs should be allocated hinges upon the mindset of which customer service came first. Most discussions speak as if residential customers are already paying for distribution service; thus, their choice of a third-party merchant presenting new costs and new charges only to those residential customers taking unbundled service are warranted. Yet, if residential customers are assumed to have choice, their prior bundled rates already incorporate a distribution fee, an access fee to a merchant, and a merchant fee. There are no new costs associated with shifting to another merchant. The access fee is still paid; all that changes is that the access fee links the customer to a different merchant. The costs associated with the merchant fee simply go to another merchant. The total billing costs do not change, only their allocation changes. This is quite similar to the access fee that became part of all telephone customers' monthly bills with the breakup of AT\&T and customer choice of their long-distance carrier.

\section{Monitoring Costs - Integrity of the Physical System}

The distributor must ensure that each third-party merchant serving residential customers is in balance between nominations and deliveries on a daily and monthly basis, just as the distributor must ensure that its own merchant service is in balance. If costs associated with imbalances arise, then penalties must be assigned to encourage better planning and to provide sufficient compensation to make the distributor financially whole.

Staff time is absorbed in the gas supply operation to perform this monitoring. A charge for this must be levied, but this charge should not exceed what is currently being 
charged an industrial transportation customer. Once spread over several or many thousands of smaller customers, the fee paid by each third-party merchant should be insignificant for the individual residential customer. ${ }^{5}$ This monitoring should be easier than for an industrial or large commercial customer given that the distributor is comparing actual deliveries with computer projected residential usage, rather than actual meter reads and reporting. Penalties are easier to assign.

The monthly charge of a third-party merchant providing firm service should be less than that of an $A B M$ providing interruptible service, for example to industrial firms. The reason for this is that the distributor does not need to be assured that residential customers exit the system at capacity peak periods.

\section{Stranded Costs}

In capacity surplus regions, as more residential customers select unbundled service, the distribution utility's merchant service may become exposed to entitlements to gas supply from producers or to pipeline capacity and storage from interstate transmission companies that are no longer required for the remaining customers. Further, if the distributor also provides local storage and supplemental peaking facilities, and residential unbundling provides choice, these services may also become exposed to lower utilization. Thus, the likelihood of significant stranded costs can be a real issue.

The magnitude of these stranded costs may be decreasing as more distributors have included one-year and three-year contracts for pipeline and storage capacity in

${ }^{5}$ Assume a monitoring charge of $\$ 2,000$ per month for each third-party merchant. If the merchant should have 40,000 customers, then the added cost amounts to $\$ .05$ per month per customer. It should be noted that once one residential customer is added, there is virtually no cost for that customer's aggregators to add another residential customer. The incremental cost to extend service for 30 percent rather than 15 percent of a residential market is negligible, particularly when the number of third-party merchants changes only slightly. 
their portfolios and a secondary market exists in which they can resell additional entitlements on capacity. Some distributors may have built into their capacity contracts ratchet-down or force majeure provisions that automatically permit ratchet-down entitlements related to customers selecting third-party merchants. Most distributors' portfolios of gas supply contracts include spot and one-year contracts. These trends indicate that the magnitude of stranded costs will likely be small given the adjustments distributors have made in contracting over the last several years.

\section{Low Load-Factor Costs}

The fact that customers with smaller gas use typically have low load factors implies their service will be more costly than service to a 100 percent load-factor industrial customer. This fact says nothing, however, with respect to whether a thirdparty merchant will be more cost effective than the distributor in providing service. Actually, it requires more management skill in obtaining cost-effective service to the low load-factor customer. Hence, permitting competition and market-driven incentives is likely to show greater improvement in reducing costs at the residential sector than at the industrial sector.

There is also the issue of achieving the greatest level of firmness required by customers who make small use of gas, for whom it is costly to relight or make sure that their pilot lights are relit, and who do not possess alternative fuel capability. Yet, some would argue that reliability provided by the distributor through firm contracts can also be achieved by third-party merchants through some combination of long-term contracts and willingness to pay market prices as needed. Peak and back-stop capacity and commodity can be bought away from others or may involve exchanges and backhauls. Reliability in this unbundled service environment may result in an enlarged role for supplementals, as well as knowledge of the price at which other customers will switch to alternative fuels.

In the current environment with high prices on peak-day transmission capacity, it is noteworthy that a large industrial user of natural gas identified success in optimizing 
gas procurement through increasing its load factor from 77 percent to 100 percent. $^{6}$ This best-cost strategy did not involve alternative fuel use to raise the load factor even higher. Could National Steel have an even more optimum procurement strategy by reselling its claim on peak capacity and commodity at peak and shifting to alternative fuels? With the advent of unbundled residential service and third-party merchants who service them, there may be lower barriers (lower transaction costs) that would result in new economies to both residential and industrial customers. The further unbundling of the distributor's services, in addition to providing choice to residential customers, opens up a market for energy merchants, not just natural gas or fuel oil, to achieve even greater economies.

\section{System Planning Costs}

Does not the uncertainty of whether core customers will actually stay with system sales service in the future, or whether those who had left for another third-party competitor actually will want to come back for system sales, raise the planning cost of the gas distributor? The answer is, "yes and no." Competition produces additional risk on system planning. Hence, the LDC incurs additional costs that it must pass on. On the other hand, the risks associated with these potential costs pressure the firm to make better management decisions that will tend to reduce the wastes below those of a firm that has a monopoly position. On net, the uncertainty could lower total costs.

\section{Equity Effects}

The variance in the monetary impact among the various participants in the natural gas industry from the unbundling of service for residential customers may be

6 Jon Rateau, National Steel Corporation, "Optimizing Gas Transportation Management: Industrial Consumer Insights," presented at the Center for Business Intelligence Conference on Unbundling Natural Gas LDCs, New Orleans, Louisiana, October 16, 1995. 
small to moderate with residential customers reaping net benefits. A greater per-unit saving is likely realized by those residential customers who initially move to direct access. Suppliers whose current services are overpriced will be the major losers. ${ }^{7}$ Suppliers whose services are most economical will be major winners. Industrial end users who lose preferential positions may still experience net gains from the general increase in new overall efficiencies. The wealth transfers are less within and among customer classes than between consumers of natural gas and particular suppliers and those parties holding current contracts for their supply.

Unbundling will compel terms of service to reflect those most sought by consumers and the prices of these competitive services will become cost based. ${ }^{8}$ Unbundling residential services primarily affects the contracting costs for commodity, storage, transmission capacity, and supplemental supplies. Unbundling may also affect billing and meter reading, and so forth. These associated costs are primarily variable costs; the utility can therefore easily cut back these services without affecting remaining customers or its bottom line. ${ }^{9}$ The dimensions to the equity impact will be approached through a series of questions.

7 Interstate pipelines and storage operations face the most risk as there is likely little regulatory ability to shift uncollected revenues from other parties in the current environment. Local distributors also face risk, but these shortfalls of projected revenues may be shifted to services wherein these dollar flows can be recouped.

${ }^{8}$ In a competitive environment, in the long term cost-based and value-based rates are equal. That is, if value-based rates exceed costs, then entry will occur and tend to drive prices down and costs up until they equate. Cost-based rates appear equitable: no customer class is subsidizing the use of natural gas by another class. Yet, the allocation of common costs among customers and by period of use is not so clear-cut.

${ }^{9}$ Unbundling residential service largely does not affect the costs associated with the provision of the distribution grid, compression and meters, or the costs of controlling gas flows. These cost allocations are a major issue at the state level but are not necessarily an unbundling issue. 


\section{QUESTION 1:}

HOW IS THE EQUITY IMPACT

OF UNBUNDLED RESIDENTIAL SERVICES

LINKED TO TRANSMISSION-CAPACITY CONTRACTING?

Pipeline rate design is based upon the allocation of all fixed costs upon those with peak day entitlement; many state commissions pass through these costs in like fashion. Unbundling provides choices to core customers whose current bills may inaccurately reflect the cost of peak-day gas usage. With unbundling, marketers, in addition to those who are more clever in contracting ${ }^{10}$ may provide accurate prices. As a consequence, customers willing to economize on peak usage will gain more economical service. Unbundling increases pressures for accurate prices and may reveal unused and unuseful pipeline and distribution capacity. The equity effect originates from a decrease in the price for firm entitlement but an increase in the price for secondary capacity. Interestingly, the equity impact hurts industrial end users who seek full gas usage via interruptible or secondary capacity. However, the industrial end user with dual fuel may be assisted by residential unbundling and new contracting practices. ${ }^{11}$

Overall, the finding here is that there could be (1) a major transfer from pipelines to residential consumers, (2) some transfers from interruptible customers who seek firm service, (3) some wealth gains by interruptible industrials who can plan for interruptions, and (4) general gains to all end-use customers from greater efficiencies.

10 New merchants may destroy the perception that firm service requires 100 percent entitlement to peak capacity. Rather, firm service can be provided by paying the highest spot price or developing offsetting quasi-firm load with large customers who possess dual fuel capability. Marketers on behalf of residential customers may be buyers in the secondary market, not simply sellers as typically is the case with gas distributors.

${ }^{11}$ The negative wealth impact upon the industrial gas user is offset by increased operating efficiency (that is, lower costs) that results when the distributor has a physically separated merchant service and current impediments are reduced or removed. 


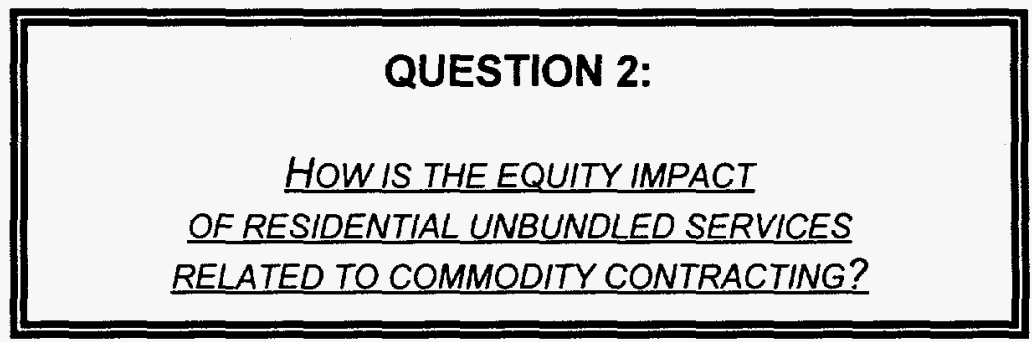

Some distributors currently contract with gas producers on behalf of their core customers wherein an additional payment is made to the producer as compensation for holding gas reserves not produced in periods when demand by the distributor is low. The contract offers a continually adjusting competitive market price plus this premium. Such contracts have the principal effect of increasing the price paid by residential customers and the price received by the producer. They have a small negative effect upon the spot-market price for natural gas - the price which most industrial end users pay.

Residential unbundling is likely to find more agents for residential customers, ending the payment of premium prices for natural gas; the effect is that producers will experience lower revenues, and assuming some imperfection in the capital market for exploration and development of natural gas, drilling will fall somewhat and wellhead prices will rise. ${ }^{12}$ Residential customers who selected third-party merchants gain; those end users who in the past relied on spot supplies lose as the prices for the type of supply they had purchased become slightly higher.

${ }^{12}$ Residential unbundling permits the offering of a specialized package of more stable long-term supplies. Such service has value to some consumers and some producers; unbundling can permit greater efficiency by lowering risks and may result in higher prices for some services. 


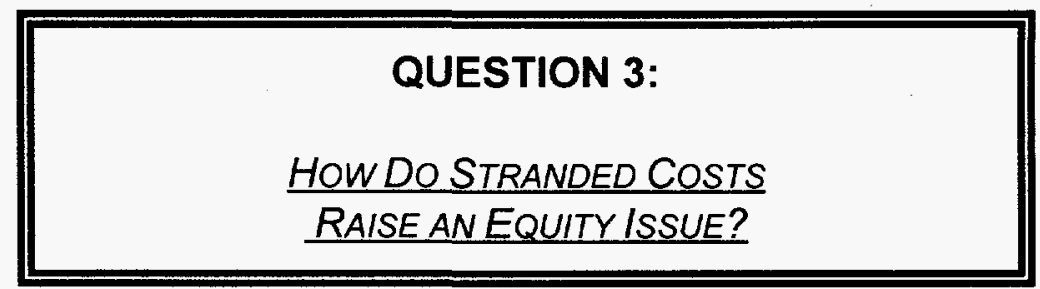

Once an unbundled environment is developed, a merchant cannot serve any one class of customers with services whose quality exceeds the customers' desired level or whose costs exceed the competitive price. Unbundling can expose the utility's contracts as being commercially impractical; it can also expose some of the utility's services as having insufficient value. If these contracts or services have fixed costs and their resale value on the secondary market does not fully compensate the distributor, then stranded costs arise. In the transition, these costs must be allocated. This allocation has an equity impact.

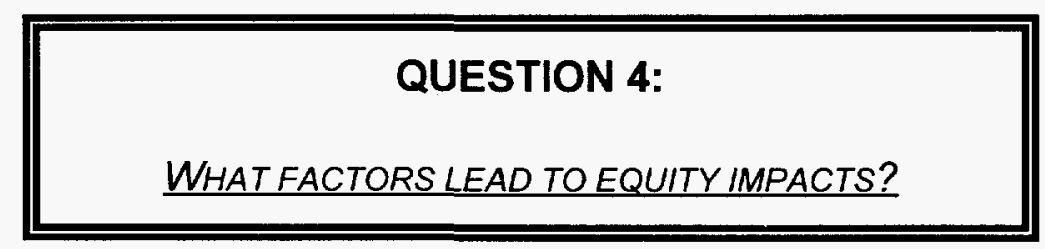

First, unbundling increases the pressure upon the distributor to contract on behalf of its core customers in a more market-sensitive fashion. The result can be lower core-customer rates even without any customers shifting to third-party merchants. This first effect is a win-win situation (equity increases within the utility's service areas), although suppliers to the distributor may have lost some surplus returns previously captured. Unbundling limits the ability to capture prices above competitive levels from particular customer classes. If allowed, unbundling provides the opportunity for other merchants to enter those submarkets. Generally speaking in the natural gas industry, 
equity is not served by bifurcating the market and designating higher mark-up over cost of service to price inelastic customers, namely residential customers.

Second, as individual services become unbundled and separately priced, a greater chance exists that market pressures are going to reveal some services (1) which have been mispriced in the aggregate, (2) for which some customer classes have been subsidizing other classes, (3) for which some customers may be willing to do without, and (4) for which third-party entities have greater efficiency in providing. (The clarifying example in Table 5-4 focuses on current mispricing.) These unbundlings should generate efficiencies and wealth transfers should also transpire.

Third, when the current rate structure of the distributor is cost based, the equity effects of expanded unbundling of the distributor's services are likely smaller. Fourth, where the distributor's current contracting is already "best cost," unbundling services is more apt to result in voluntary repackaging by consumers similar to the initial bundled services. Hence, equity issues are attenuated. Finally, with more contracting alternatives available to merchants, the more adept third-party merchants can devise better priced services.

\section{Have LDCs Gained from Bundled Service?}

Starting in the mid- and late-1980s, when forced by regulatory mandates and market pressures, LDCs were unwilling to unbundle their services. Bundled services were presumably attractive to LDCs. The question of how LDCs benefited from offering only bundled services is not at all evident. Bundling of services and products is a common phenomenon throughout economic systems. In the economics literature bundling is regarded as a marketing strategy that mostly arises for the following reasons: (1) cost economies, (2) technological interdependency, and (3) demand interdependency. ${ }^{13}$

${ }^{13}$ See, for example, Roger Blair and David L. Kaserman, Antitrust Economics (Homewood, IL: Richard D. Irwin, Inc., 1985), Chapter 15; and Dennis W. Carlton and Jeffrey M Perloff, Modern Industrial Organization, 2d edition (New York, NY: HarperCollins College Publishers, 1994), 841-43. 


\section{TABLE 5-4}

\section{CLARIFYING EXAMPLE: HOW UNBUNDLING MAY LEAD TO COST-BASED RATES}

Assume residential customers are charged from the same rate schedule, and these customers can be divided into three classifications, namely,

Class A: Use natural gas just for cooking, heating water. High load factor. All social demographic groups.

Class B: Use natural gas for space heating, water heating, and possibly for cooking and clothes drying. Low load factor. No discernible difference in load pattern whether use is small or large. All social-demographic groups.

Class C: Use natural gas as back-up for electric heat pump. Very low load factor. Typically, above average social-demographic household.

With regard to purchased capacity costs:

The demand charges of the pipeline will fall proportionately more on Class A and less on Class $\mathrm{C}$. Class $A$ is subsidizing other residential customers and Class $C$ is being subsidized by others. Thirdparty merchants would offer service tailored specifically for Class A with lower transmission costs associated; and we will observe their shift in merchants. If the distributor does not react, then rates for Class $B$ would be too high because Class $B$ would now be covering part of the costs to serve Class $C$. Merchants would now target Class B customers, and they would shift.

\section{With regard to commodity costs:}

With regard to the three customer classes, Class A customers are the easiest to contract - little storage is required and there is largely an even flow from the producer. Class $C$ customers require the commodity at its most costly period and when capacity is most scarce. Once again, a merchant will target Class $A$ with a subsidy-free rate and these customers can be expected to shift revealing commodity costs in serving Class $C$ that the distributor must charge them or pass on to Class $B$ customers. If the latter, then Class B will commence to leave.

\section{Ceasing cost-shifting and equity}

This example demonstrates that unbundling commences a process which reveals cross-subsidies. Through customer choice, cost-based rates for services will emerge with or without the distributor's participation. Second, wealth transfers which result from ending prior divergence of revenue responsibility from cost causation must be viewed as increasing equity. Residential Class $C$ customers who experience an increase in rates reflecting their higher cost of service have an above-average income. Residential consumers gain at the expense of inefficient suppliers; a more level playing field with large end users of natural gas is also an equity plus.

Source: Authors' construct. 
Cost economies, or what is commonly called "economies of scope," refer to cost savings attributable to one firm producing and selling different services together as a package. For example, an LDC may be able to provide retail gas service at a lower cost to consumers when it combines gas supplies, transportation, and storage into bundled sales service. By coordinating these services on its gas system an LDC can realize cost savings that would otherwise not accrue. Empirical evidence of economies of scope at the distribution level is scant. ${ }^{14}$ To the contrary, in the case of transportation programs for industrial customers, most eligible customers opted for unbundled service. This suggests that any lost economies that may have accrued were more than offset by cost reductions from competitive pressures. An LDC's bundled sales service could not successfully compete with unbundled services that became available. Simply, bundled sales service failed the market test: notwithstanding any economies of scope, consumers found it beneficial to purchase gas-service components on an unbundled basis. $^{15}$

A firm may also wish to offer only bundled service or products because of technological interdependency..$^{16}$ In the case of natural gas, highly reliable retail gas service is crucial. Reliability depends upon the availability of upstream pipeline capacity, storage, gas supplies, and distribution. The value that retail gas consumers place on an LDC's overall service is therefore assembled from the value of individual components. LDCs may have felt that supplying those service components directly to

${ }^{14}$ Some evidence of economies of scope for LDCs is presented in Mary Lashley Barcella, "Natural Gas Distribution Costs and Efficiency: Implications for Regulation," unpublished paper (February 1993), 15. But the author cautions that:

[T] he design of the study does not allow a clear test as to whether the source of natural monopoly [economies of scale and economies of scope] is in the gas distribution activities of LDCs, the gas purchase/sales activities, or a combination of the two. To the extent that economies of scale and scope are present in one function and not the other, it may be possible to unbundle gas distribution from gas purchase/sales without adverse effects.

${ }^{15}$ It may be argued that unbundling could actually increase economies of scope and economies of scale by allowing large merchants, such as Enron, Tenneco, and AMOCO to replace smaller LDCs in the provision of gas supplies and upstream pipeline services.

${ }^{16}$ See, Blair and Kaserman, Antitrust Economics, 382-83. 
retail consumers in the form of bundled service would best assure highly reliable service. ${ }^{17}$ Unreliable service could jeopardize both the goodwill and reputation of an LDC in the eyes of its consumers and regulator.

Experiences in service unbundling at the pipeline and retail levels have so far attested to the invalidity of this argument. Customers or their agents have the incentive and capability to contract for individual services with high reliability. Presumably, there is nothing especially difficult about contracting for highly reliable gas services that only an LDC could perform. In other words, no reason exists for the LDC to be the most efficient and only competent intermediary of gas services. The more relevant question is whether the transaction costs of purchasing and combining unbundled services exceed or fall short of the savings achieved by customers when allowed to purchase their own services in the marketplace. As discussed above, gas consumers and their agents have done quite well in purchasing and combining individual gas services.

Firms also bundle services and products as a tool of price discrimination. ${ }^{18} \mathrm{By}$ forcing the tying of complementary services, for example gas supplies and gas transportation, a firm has the ability to separate customers into groups with different demand characteristics. Economic theory shows that bundling allows a firm to extract more consumer surplus than it would under unbundling or uniform monopoly pricing. ${ }^{19}$ Most of these instances require that the demand for the individual services or products are interrelated. For example, assume that a firm rents carpet cleaners and requires the purchase of cleaning fluid. By selling the cleaning fluid above the competitive price,

${ }^{17}$ Marion B. Stewart, Vice President of the National Economic Research Associates, offered this idea to one of the authors.

${ }^{18}$ Most economists would argue that price discrimination, rather than monopoly leveraging, is the more logical reason why most firms bundle their products or services. Accepting this argument, one cannot say deductively that all bundling is necessarily socially undesirable. In fact, some bundling motivated by price discrimination has undoubtedly increased economic welfare. (See William James Adams and Janet L. Yellen, "Commodity Bundling and the Burden of Monopoly," Quarterly Journal of Economics 90 (1976): 475-98.)

${ }^{19}$ See Carlton and Perloff, Modern Industrial Organization, 470-79. 
the firm, in effect, earns a higher rent on the carpet cleaner. ${ }^{20}$ Putting it another way, the firm would receive revenues on the carpet cleaner equal to the rental rate plus the economic profit earned from selling the cleaning fluid. Consumers who use more cleaning fluid would in effect pay a higher rent for the carpet cleaner. Consistent with price discrimination, those who more intensively operate the carpet cleaner (thereby placing more value on the carpet cleaner) would pay a higher price.

The extent to which LDCs have benefited from service bundling through price discrimination is not altogether clear. Take the example where an LDC combines gas supplies and distribution into bundled sales service. Both service components are subject to price regulation. The gas costs associated with gas supplies are typically passed through dollar-for-dollar to consumers. The LDC receives most of its profits from distribution service, where the depreciated physical assets earn an allowable rate of return commensurate with the cost of capital. Assume, for whatever reason, an LDC has the ability to price gas supplies above cost, or to earn above-normal profits for the parent company from an affiliate transaction. The return on distribution service earned from individual customers would then depend upon these customers' actual gas usage. Take two customers who pay the same demand charge, but one customer consumes more gas than the other. If the LDC prices gas supplies above cost, the higher-usage customer would in effect be contributing more toward distribution costs. This would be true even though "on the books" she would be paying the same amount for distribution as the other customer.

In examining the past benefits of bundling to LDCs, the influence of regulation must be taken into account. State regulation limits the profits of LDCs mostly by guarding against excessive price discrimination and overcharging of inputs (for example, gas supplies). This implies that an LDC could not recover excessive

${ }^{20}$ This example follows the antitrust case where IBM was accused by the federal government of anticompetitive practices by requiring purchasers or renters of its tabulators to buy all of their tabulating cards from IBM. (See IBM v. United States 298 U.S. 131 (1936)). 
revenues from gas supplies to discriminate against higher gas-usage consumers. In theory, if regulation achieves its objective, an LDC could not use service unbundling as a form of price discrimination. For example, if LDCs are unable to overcharge for gas supplies, then recovery of distribution charges would not vary with consumer gas usage. In practice, however, mainly because of information asymmetry, LDCs may be able to mark up the price of gas supplies. Especially when an LDC purchases gas supplies from an affiliate, it is not an easy task for a regulator to prevent excessive payments by an LDC. ${ }^{21}$ This possibility was more likely in the past when a spot and futures market for gas did not exist. In that environment it was difficult for a regulator to identify an appropriate reference price from which to evaluate individual gas purchases. Assuming that an LDC could mark up the price of affiliated gas supplies, it could then exploit service bundling as a price discrimination tool. The likelihood of this outcome is greatly enhanced when third-party gas suppliers are hampered in selling gas supplies directly to the retail market. Otherwise, the LDC would have an incentive to purchase the lowest-cost gas supplies or to make available those sources of gas supplies to retail consumers.

\section{Major Outcomes of Unbundling and Repackaging}

Several general points can be made here about the effects of unbundling and the packaging of unbundled services. First, unbundling per se gives consumers more market choices. Consumers can always add up the prices of individual components and compare them with the price of a bundled service or any combination of bundled and unbundled services. Consumers would tend to select the alternative with the lowest aggregate price, assuming quality and other product attributes are the same.

${ }^{21}$ The problem of affiliated transactions for regulators is examined in Mohammad Harunuzzaman and Kenneth W. Costello, State Commission Regulation of Self-Dealing Power Transactions (Columbus, $\mathrm{OH}$ : The National Regulatory Research Institute, 1996). 
Unbundling should rarely harm consumers and almost always benefit them. ${ }^{22}$ If consumers could make the same choice as before but now have additional choices, it is logical to conclude that they should be better off.

Second, wholesale service unbundling may fall short of maximizing benefits to retail customers. In the case of the natural gas industry, FERC Order 636 and previous FERC orders led to the unbundling of pipeline services. Currently, a major issue surrounding public utility restructuring is, To what extent do wholesale competition and wholesale service unbundling fall short, if they do, of maximizing benefits to retail consumers? If one believes that additional benefits from retail service unbundling are small, then from an economic perspective it can be argued that we do not need it. An analogous debate exists in California between the "Poolco" advocates and the "Direct Access" advocates. ${ }^{23}$

On the other hand, in line with experiences across different industries and with economic theory, retail service unbundling may be a necessary condition for a fullycompetitive natural gas industry. The basic economic argument is that only retail consumers themselves, or their designated agents, can decide what is in their best interests. The wholesaler, or the LDC in the case of natural gas, just does not have a strong incentive or the ability to maximize consumer well-being. The principle that what is good for firms is good for consumers only holds under competitive conditions. So to argue that retail competition induced by service unbundling is not a necessary condition for maximizing consumer interests generally conflicts with market realities. To confirm

${ }^{22}$ Conceivably, the forced purchase of unbundled services could cause an industry's costs to rise, for example because of lost scope economies, and thereby increase prices to consumers. As discussed elsewhere in this report, requiring small customers such as residential households to purchase all of their gas services on an unbundled basis would be ill-advised. Other potential adverse effects of unbundling of public utility services originate mainly from regulatory practices. For example, the fact that unbundling may cause cost shifting, with the consequence of higher prices for some customers, is mostly an equity issue largely arising because of cost-of-service regulation.

${ }^{23}$ See, for example, Matthew C. Hoffman, "The Future of Electricity Provision," Regulation 17, no. 3 (1994): 55-62. 
this, just ask the rhetorical question: Would the products and services we buy today be as cheap or as differentiated if retail outlets had exclusive rights to sell in a specific geographical area?

Third, as discussed elsewhere in this report, forcing a firm to unbundle all of its subservices may harm consumers. This could particularly hold true for small customers. These customers would tend to have higher transaction costs, say, per unit of gas services consumed. Therefore, requiring them to search out and negotiate with providers of different gas services may impose upon them a high cost. Of course, it would not be unreasonable to believe that market facilitators, for example aggregators, brokers, and others, would try to lower those transaction costs. In any event, offering both bundled and unbundled service, at least during initial periods, for small customers would seem preferable to mandatory service unbundling.

Fourth, the optimum degree of unbundling has a limit. For example, technically one could purchase different parts of a car from the different vendors and have someone assemble the car. In effect, the person would be purchasing unbundled products and combining them to make a product from which the consumer directly benefits. Instead, for most products and services consumers prefer to buy the "finished product" rather than a "kit." Time considerations, the cost associated with assembly, and other factors contribute to consumers frequently preferring the finished product.

In the case of retail gas markets, two questions relating to the optimal degree of unbundling are particularly relevant: (1) For which customers would service unbundling be economical? (2) How far should service unbundling behind the city gate extend? Regarding the first question, service unbundling may be unattractive to some customers (for example, small customers). But, as discussed above, so long as these customers can choose between unbundled and bundled sales services they are no worse off. Because some other customers would be better off, overall net benefits should be positive.

With respect to the degree of unbundled behind-the-city-gate services, the concept of economies of scope becomes relevant. Economies of scope refer here to the cost savings from the LDC, rather than different entities, providing a set of gas 
services demanded by consumers. This means, for example, that costs can be reduced when the LDC uses its physical assets to jointly provide distribution, on-system storage, peaking, and balancing services. Economies of scope encompass what is sometimes called "economies of vertical integration" or "economies of coordination." One major factor of economies of scope is knowledge. Knowledge of one activity may promote the efficient production of others. Another factor is the complementary relationship between a firm's physical assets. For example, gas distribution and onsystem storage may be less costly when provided together. A necessary condition for economies of scope is deployment of common inputs in the provision of two or more services. Economies of scope, however, do not necessarily imply the desirability of having one entity providing the different services. Separate entities operating under a contract could achieve the same economies of scope as a single entity could. In other words, coordination of services using the same physical assets could be accomplished in the absence of single ownership.

Fifth, service unbundling could diminish certain economic problems associated with a regulated public utility. The major ones include productive and pricing inefficiencies. Service unbundling would place pressure on the LDC to eliminate any cross-subsidies that may currently exist and, in general, to price individual services on the basis of actual market conditions or economic costs. By allowing entry, service unbundling also places competitive pressures on the LDC to operate and plan more efficiently or else risk losing sales and profits to more efficient service providers. ${ }^{24}$

Sixth, over the short term, service unbundling per se may not necessarily improve economic performance in the natural gas industry. Unbundling in one sense places more pressures on the industry to be efficient: the increased competition induced by unbundling constrains service providers to focus more on economicefficiency objectives and less on others. Over the short term, however, in an environment with old regulatory rules and transition problems, economic performance may actually worsen. Inefficient pricing of unbundled services, risk-allocation

\footnotetext{
${ }^{24} \mathrm{~A}$ more detailed discussion of this argument can be found in Chapter 7.
} 
distortions, ${ }^{25}$ high transaction costs, initial mistakes by consumers, transitory monopoly behavior, and outdated regulatory rules in general can all contribute to declining economic performance. These problems should diminish over time because of economic and political pressures. As in many real world situations, when regulatory and industry practices act contrary to market realities, change becomes inevitable. Interest groups and regulators themselves would find it beneficial to reassess current practices and search for new ones that are more in line with actual market conditions. Failure to act accordingly would sustain the new inefficiencies, translating into less wealth for certain interest groups and society at large.

The main idea conveyed here is that for service unbundling to be economical it must function in a market and regulatory environment where efficiency and consumer responsiveness determine the success of different service providers. Outcomes induced by regulatory and market malfunctions violate this condition. These malfunctions may include entry barriers, rigid regulatory pricing, and obligation-to-serve rules, and discriminatory access to natural-monopoly facilities. Any of these could induce inefficient performance of the natural gas industry.

One may ask what benefits accrue to retail consumers when they purchase rebundled or "package" services from the LDC rather than the old bundled sales service. Would not consumers be essentially receiving the same gas service and, just as before, be paying one price?

Although the answer is "yes" to each of these questions, rebundling would be expected to benefit consumers. The simple reason is that consumers would have more choices under rebundling. In that world, consumers could choose among different combinations of gas services offered by available gas service providers. Because of these opportunities for consumers, competitive pressures should constrain the "total price" below what it would be in the old bundled-sales-service world. Throughout the economy, "package" services are often sold at a discount relative to individual

${ }^{25}$ Risk-allocation distortions would result, for example, if the LDC continues to be the "supplier of last resort" without being adequately compensated. Any market risk that becomes external to the decisionmaker represents a risk-allocation distortion. 
components. ${ }^{26}$ One could pose the following "thought experiment:" How would the prices of the products and services we buy today change if unbundling was prohibited?

For example, assume that we are required to buy all of our personal computer needs from a single retailer who had exclusive territorial rights. Also assume that the retailer was unwilling to sell separate hardware and software components. In other words, a consumer would have to purchase a bundle of personal computer products to satisfy her needs. It is safe to say that, compared to today, consumers would pay more for personal computer services. When individual components can be sold by themselves or in a package, the ability of the retailer to price discriminate or to set an excessive price lessens. By revealing the prices of individual components, unbundling imposes a tighter limit on the price charged for bundled or rebundled service. In effect, by giving consumers more market choices, unbundling diminishes the degree of price discrimination (though does not eliminate it). For many products, the rebundled service sells for less than the sum of its components. ${ }^{27}$ It can be said that this discount reflects a form of discriminatory pricing that is good for consumers and society at large.

${ }^{26}$ As an example, if consumers had to purchase each component of an automobile, the total cost would be substantially higher than the cost of a packaged or finished automobile that virtually all consumers buy.

${ }^{27}$ One could think of products or situations where the opposite is true. For example, some rebundled products may cost more in countries with high value-added taxes. 


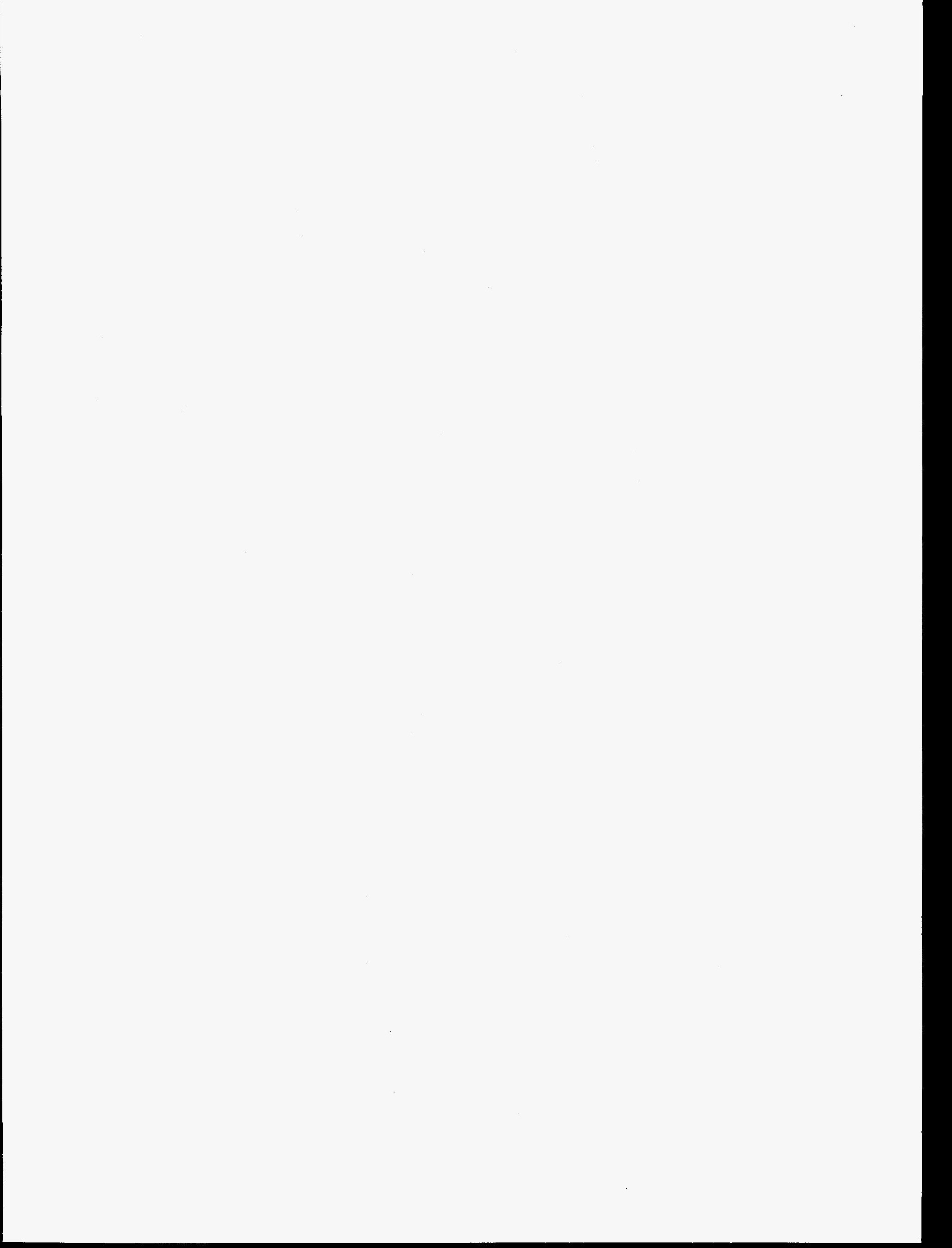




\section{CHAPTER 6}

\section{OPPOSING POSITIONS}

\section{Skeptics of Residential Service Unbundling}

Stephen Huntoon of PECO Energy Company has been an outspoken opponent of residential service unbundling. ${ }^{1}$ He raises several questions that warrant serious consideration by regulators and advocates of residential service unbundling. This report, in various chapters, addresses his major concerns and generally concludes that Huntoon's criticisms of residential service unbundling, although legitimate in some instances, are not fatal to the concept.

Huntoon sees service unbundling to the core market as inevitable. ${ }^{2}$ He believes, however, that unless structured properly such unbundling would produce no more than a wealth-distribution outcome where marketers benefit at the cost of additional risks to LDCs and their customers. Specifically, as a major charge, Huntoon argues that the cost savings promised by marketers do not reflect improvements in economic efficiency. Instead, they largely result from marketers using nonfirm pipeline capacity to supply the firm requirements of core customers. Overall, Huntoon strongly contends that marketers exist only because they are able to take advantage of existing rate and tax structures.

Huntoon asks the fundamental and relevant question, Where are the cost savings? He goes on to comment that one has to look hard to identify areas of cost

1 See Stephen L. Huntoon, "Restructuring LDCs for the Competitive Environment," presented at the 27th Annual Conference of the Institute of Public Utilities at Michigan State University, Williamsburg, Virginia, December 11, 1995; Stephen L. Huntoon, "636 to the Burnertip?" Public Utilities Fortnightly (July 1, 1994): 22-25; and Stephen L. Huntoon, "Barbarians at the City Gate," Public Utilities Fortnightly (September 15, 1995): 54-57.

2 Ibid., "Restructuring LDCs for the Competitive Environment," 1. 
savings from service unbundling. He argues, for example, that LDCs currently pay the market price - the same price that marketers would pay - for wellhead gas; thus, there appears to be no savings in commodity gas. With regard to interstate transportation, Huntoon argues that, at least up to now, pipeline restructuring has had no noticeable effect on pipelines' cost of service. He acknowledges, however, that marketers may be repackaging upstream pipeline services more efficiently than LDCs. He also recognizes that gas marketers can realize savings in the price of pipeline capacity.

Regarding distribution, he argues that the cost of delivering gas beyond the city gate should not change when third-party gas is involved. Overall, Huntoon sees the advantage of marketers originating mostly from the fact that they do not have to pay a gross receipts tax on the gas they sell. In many, if not most, states the commodity sale of gas by any entity other than a regulated public utility is exempt from the gross receipts tax.

As a potentially damaging argument, Huntoon concludes that cost savings to core customers from service unbundling do not reflect economic efficiency gains. Instead, they result from cost advantages given to marketers because of tax discrepancies and subsidies funded by LDCs (more on this in Chapter 7). Overall, Huntoon believes that unbundling services for small customers will yield small if not negative returns to society at large.

Huntoon also makes the point that the service offered by marketers is less reliable than bundled sales service. He characterizes the service offered by marketers as "virtual firm service." Such service relies on released pipeline capacity that is recallable by the releasing utility, levers firm service by contracting for firm capacity below the aggregate customer peak-day load, and relies on balancing tolerances and LDC-owned gas to cover the peak-day customer load. Given these descriptions, Huntoon argues that unbundled service customers would probably continue to receive firm service but at a cost to the LDC. In other words, the LDC would be subsidizing unbundled service customers by guaranteeing firmness of service at an uncompensated price. 
Another problem that Huntoon identifies is the existing obligation-to-serve rules. He argues that these rules would have to be removed. He comments that they are incompatible with a competitive market where consumers can choose among suppliers by giving consumers improper price signals. By underpricing the risks associated with unbundled service, some customers would want unbundled service even when the true societal cost of such service exceeds the LDC's cost. Huntoon argues that, if customers want the right to choose suppliers, they should bear the consequences of interruptible service and other undesirable outcomes.

Huntoon identifies what he believes are newly created costs from service unbundling to core customers. These costs stem from marketing activities, consumer fraud, the transaction process, and oligopolistic pricing.

Huntoon also points out that any benefit received by core customers from unbundling could not derive from cost shifting. He argues that, over the last ten or so years, unbundling has benefited large customers partly because of the ability of LDCs to shift costs to core customers. With core-customer unbundling, the LDC has no one to shift costs to. Therefore, he concludes that the benefits to those customers become greatly limited.

In sum, Huntoon sees little merit in unbundling gas service to core customers. It seems to these authors that he exaggerates the costs and understates the benefits of service unbundling to small customers. ${ }^{3}$ He does, however, raise some valid points about where the benefits of unbundling will come from and why existing obligation-toserve rules can distort industry performance in a service-unbundling world.

Another critic of service unbundling to small customers is Professor Richard J. Pierce, Jr. Pierce has serious reservations about the efficiency of allowing small retail customers to purchase unbundled gas services. ${ }^{4}$ Normally a promarket supporter, he

${ }^{3}$ Other sections of this report make arguments that contradict his benefit-cost assessment of residential service unbundling.

${ }^{4}$ Richard J. Pierce, Jr., "Intrastate Natural Gas Regulation: An Alternative Perspective," Yale Journal on Regulation 9, no. 2 (Summer 1992): 407-16. 
conjectures that for these customers, the benefits of unbundling would fall short of the costs. He identifies market transaction costs, for example, the required time and other resources for searching out and negotiating with different service providers, as the primary cause of an uneconomical outcome. Pierce acknowledges, however, that transaction costs can be seriously reduced by market intermediaries providing a package of unbundled services. ${ }^{5}$

Even if small customers want to unbundle their gas services, Pierce says the results could be economically bad. One source of the problem would arise from LDCs assuming the risks without adequate compensation of gas nondeliveries. By externalizing this risk to the LDC, consumers would tend to underestimate the cost associated with unbundled services. Pierce also questions the ability of cost studies, especially those applying embedded-cost methods, to derive correct rates for backup service. Even if they could, he argues that the sum of the costs of unbundled services would probably exceed the cost of bundled sales service.

In sum, similar to Huntoon, Pierce sees little or no economic gains from service unbundling to small customers. In fact, both Pierce and Huntoon contend that economic distortions would likely be the outcome.

\section{Proponents of Residential Service Unbundling}

Marketers are currently the strongest supporters of residential service unbundling. Enron Capital and Trade Resources (Enron) in particular has been active in promoting service unbundling across all classes of customers. ${ }^{6}$ Enron's major

5 In fact, one can argue that the function performed by market intermediaries may be indispensable for any successful residential service-unbundling program.

6 Tenneco Energy Resources has also been active in promoting unbundling for all classes of retail customers. See, for example, the comments and oral arguments of Tenneco for the Georgia Public Service Commission's Notice of Inquiry on Transition to Increasing Natural Gas Competition on December 21, 1995 and January 31, 1996, respectively. 
arguments in favor of comprehensive service unbundling are discussed below. ${ }^{7}$ Also discussed are the reasons why Enron believes such unbundling can be efficient and compatible with standard regulatory objectives.

Enron's overall position is that state regulators should move as quickly as possible in opening up service unbundling to residential customers. Enron, as well as other proponents, sees comprehensive service unbundling as a prerequisite for a highly competitive retail gas market. ${ }^{8}$

Table 6-1 lists Enron's stance on specific elements of residential service unbundling. Enron argues that load aggregation of upstream gas services would be necessary to hold transaction costs at a tolerable level. It proposes that gas suppliers be allowed to aggregate customers into a pool similarly to how an LDC currently aggregates its retail customers. There would be no minimum volume threshold for firm transportation. Enron argues that automatic meter reading would not be required for small transportation customers. It recommends that gas marketers meet specified minimum financial requirements. It also agues for separate rates for each service provided by an LDC. The rates should be cost based and exclusive of any gas-supply related costs.

Enron contends that residential service unbundling presents no technical problem and should be economically efficient if properly executed. It agrees that unbundling warrants a change in existing obligation-to-serve and pricing rules. For example, Enron argues that contracts should replace regulatory rules in specifying obligation-to-serve requirements. Enron recognizes that customers should take full responsibility for their actions: they must suffer the consequences of undesirable outcomes as a quid pro quo for reaping the rewards of lower gas costs.

7 These arguments can be found in Enron's comments filed before the Washington Utilities and Transportation Commission's Gas Notice of Inquiry (Docket No. U6-940778) on September 27, 1995 and the Georgia Public Service Commission's Notice of Inquiry on Transition to Increasing Natural Gas Competition on December 20, 1995.

${ }^{8}$ See also Pamela L. Prairie, "Retail Unbundling: Changing the LDC Business Structure and the Regulatory Process to Promote Competition," presented at the 27th Annual Conference of the Institute of Public Utilities at Michigan State University, Williamsburg, Virginia, December 11, 1995. 


\section{TABLE 6-1}

ENRON'S POSITIONS ON RESIDENTIAL SERVICE UNBUNDLING

- Comprehensive unbundling should occur as soon as possible.

- Regulation would still be required for noncompetitive services.

- Customers should take full responsibility for their actions.

- At least initially, backup service could be mandatory.

- PUC should establish guidelines for creating a "level playing field" (e.g., standards of conduct for LDC marketing affiliates).

- Contacts should dictate obligation-to-serve rules.

- Exit fees would be inappropriate.

- PUC should refrain from regulating and certificating gas marketers.

- Unbundled rates should be cost based.

- Automatic meter readers would not be necessary.

- Load aggregation would be required.

- Minimum financial requirements should be imposed on marketers.

- LDC, when given ample time, should be able to take back former bundled sales customers with minimal difficulty.

- Marketers can find efficiencies in gas procurement and transportation unavailable to, or unexploited by, LDCs.

- Service unbundling will first require LDCs to exit the gas merchant business as a regulated entity.

- To avoid stranded costs, in the short term marketers should perhaps be required to purchase an LDC's firm pipeline capacity at regulated prices.

- LDCs should be compensated for supplying backup gas. 


\section{CHAPTER 7}

\section{INDIVIDUAL SPECIFIC POLICY ISSUES}

Residential service unbundling will accelerate and broaden competition in the retail gas sector. As such, it requires regulators and LDCs to revisit existing practices and policies that were largely designed for a highly monopolistic environment.

Residential service unbundling without accompanying changes in the scope and the fundamental tenets of regulation could create problems that would diminish benefits. Regulatory reforms in pricing rules, obligation-to-serve requirements, planning guidelines, social-activities requirements, and corporate structure will be necessary if maximum benefits from residential service unbundling are to be realized.

Some regulators may believe that unbundling can be executed with only minor changes in regulatory rules. Trying to "wait until all the pieces are in place" or to "fine-tune" change, could excessively delay beneficial actions. Instead, one could embark on the new activity and deal with specific problems as they arise. ${ }^{1}$ It is highly likely that if residential service unbundling precedes necessary regulatory reforms, economic pressure would inevitably mount for such reforms. Without them, the market would perform inefficiently and some interest groups would demand regulatory changes. These changes would be geared toward enhancing both the economic performance of the industry and the economic well-being of those interest groups. In other words, regulatory reforms would arrive sooner or later.

This chapter examines several policy issues associated with service unbundling, particularly with regard to residential customers. For the majority of them, no easy

1 An emerging development in some states is to institute pilot or experimental programs that accumulate information on consumer acceptance and the performance of the availability of service unbundling to residential customers (see Chapter 2 for a summary of these programs). Specifically, pilot programs can help to demonstrate the feasibility of unbundling, identify major problem areas, and educate consumers about the benefits and costs of unbundling. 
resolution exists. These issues will be debated at the state level, in some instances with interest groups taking highly divergent positions. Table 7-1 lists the major ones. A detailed discussion of some of these issues follows.

\section{TABLE 7-1}

\section{SPECIFIC ISSUES SURROUNDING} RESIDENTIAL SERVICE UNBUNDLING

- Availability/pricing of upstream pipeline services

- "Stranded" costs

- Cost shifting

- Planning for unbundled services

- Participation of LDC affiliates to sell unbundled services or to repackage services

- Availability/pricing of standby service

- Pricing of unbundled services

- Obligation-to-serve rules

- Responsibilities/qualifications of load aggregator

- Creation of "level playing field"

- Barriers to unbundling

- Minimization of transaction costs

- Continuation of subsidized services

- Required customer information/protections 


\section{Pricing Rules}

The appropriate pricing rule for an unbundled service hinges on the market environment. Services with natural-monopoly features will require some form of regulatory price control. Distribution delivery comes to mind as one LDC service, and perhaps one of only a few, that falls within this category. Pricing options include performance-based regulation (PBR) combined with fixed-variable or volumetric rate designs, embedded-cost prices, and contract prices. Time-of-use or real-time pricing can be economical assuming the metering costs lie below the gross economic benefits from market-responsive pricing. ${ }^{2}$ Under this pricing methodology, prices would be composed of an hourly gas-commodity charge and an access charge.

PBR can apply to natural-monopoly services. It can be integrated with time-ofuse pricing or other rate designs. Under certain PBR plans the LDC would have pricing flexibility in addition to strong incentives to achieve high productivity efficiency. ${ }^{3}$ One potentially large benefit of PBR in an unbundled environment stems from the inability of an LDC to increase its profits by reallocating costs from the provision of competitive services (for example, gas sales) to distribution delivery. Under some versions of PBR (for example, price caps), the price charged by the LDC would not correspond to its reported or accounting costs. Cost shifting, besides being inefficient from a pricing perspective, would diminish the incentives for cost efficiencies. An LDC could more

${ }^{2}$ Seasonal pricing, which requires no metering costs, is a less efficient variant of time-of-use pricing that will likely improve economic efficiency. See, for example, Ken Malloy, "The Holy Grail: Pursuing Complementary State/Federal Gas/Electric End-Use Policies to Optimize Gas," Proceedings of the Third Annual DOE/NARUC Conference on Natural Gas Use (Washington, D.C.: U.S. Department of Energy, 1995): 468-72.

${ }^{3}$ One such plan, price caps, can achieve these outcomes. Southern California Gas Company has recently proposed a price-cap mechanism for its nongas services (In the Matter of the Application of Southern California Gas Company [U9046] to adopt Performance Based Regulation [PBR] for Base Rates to be Effective January 1, 1996), filed before the California Public Utilities Commission, June 30, 1995.

A hybrid price-cap plan (called the "3 P Plan") that can be applied to LDCs as well as other utilities is presented in Wayne P. Olson and Kenneth W. Costello, "Electricity Matters: A New Incentives Approach for a Changing Electric Industry," The Electricity Journal 8, no. 1 (January/February 1995): 28-40. 
afford to operate inefficiently for an indefinite period to the extent that it could shift costs to those customers who have few choices of gas suppliers.

For competitive services, where the LDC lacks the ability to establish abovemarket prices for a sustained period, the LDC should be relieved of price regulation. ${ }^{4}$ If not politically palatable, any regulatory pricing rule that is executed should allow the LDC to price within a sufficiently wide band. ${ }^{5}$ Such a rule would be compatible with marginal-cost pricing, flexible pricing, contract pricing, and value-of-service pricing. ${ }^{6}$

The major task for the regulator is to align an unbundled service with the correct pricing rule. "Getting it right" is important for maximizing the economic performance of retail gas markets. Adhering to rigid pricing rules when markets are reasonably competitive can lead to uneconomic bypass and other sources of price-induced welfare losses. ${ }^{7}$ At the other end, flexible pricing rules under monopolistic conditions may produce undue price discrimination and excessive prices to customers. ${ }^{8}$

\section{LDC Planning and Operation}

As mentioned earlier in several places, service unbundling will cause LDCs to behave more like competitive firms. One consequence is that LDCs will place more

${ }^{4}$ In a competitive market, prices would gravitate toward the marginal cost of the highest-cost provider of a service. Lower-cost providers are able to earn an economic profit.

5 The band could have as its boundary points the LDC's marginal cost and a price cap that varies periodically on the basis of an "inflation minus productivity" formula.

6 The rule recognizes that LDCs would need the discretion to vary their prices quickly and responsively to changed market conditions. Although price discrimination would occur, economic efficiency should improve in relation to rigid embedded-cost pricing.

${ }^{7}$ Rigid pricing rules tend to be nonresponsive to the varying demand preferences of consumers. In other words, they fail to account for the value that consumers place on a particular service. Besides creating a "triangular welfare loss" from a price-marginal cost gap, rigid pricing can cause consumers to go with providers with the lowest prices but not necessarily with the lowest economic costs.

${ }^{8}$ When flexible pricing leads to lower revenues, relative to embedded-cost pricing, regulators must decide how these revenue losses should be allocated. Allocating them to price-inelastic consumers would drive up their prices. In cases where flexible pricing has resulted in revenue losses for electric utilities and LDCs, state regulators have allocated these losses to both shareholders and price-inelastic customers. 
emphasis on optimizing the utilization of their assets and on minimizing their capital costs. ${ }^{9}$ For those LDCs that will no longer be in the gas merchant business, primary focus will be on increasing throughput on their delivery system. ${ }^{10}$ These LDCs will engage more in selected rate discounting and other strategic practices to maximize revenues from the provision of delivery services. Consistent with increasing throughput on their systems, LDCs will try to promote end-use demand for gas. Removed from the gas merchant business, these LDCs should be indifferent to the source of the gas that passes through their systems. ${ }^{11}$

Another expected outcome of service unbundling is that the acceleration of competitive forces will limit the costs, whether capital or operating costs, incurred by LDCs to what consumers would be willing to pay for services. Under traditional ratemaking practices, a utility's actual or reported costs would determine prices. In contrast, in a competitive, service-unbundling environment, the utility would attempt first, to measure the value of individual services to customers and, second, to establish a cost ceiling for those services that would allow it to earn a minimum acceptable rate of return. In other words, under competitive conditions the value that consumers place on a product or service drives a firm's costs and prices. ${ }^{12}$ In this circumstance, costs that consumers are unwilling to pay for get absorbed by the firm.

9 To many observers of the natural gas industry, an LDC's profitability in the future will importantly depend on the ability to sustain high throughput and sales on its distribution system.

${ }^{10}$ See Branko Terzic, "State Approaches to Natural Gas Re-Regulation," presented at the 27th Annual Conference of the Institute of Public Utilities at Michigan State University, Williamsburg, Virginia, December 11, 1995.

${ }^{11}$ Of course, if LDCs form marketing affiliates they would tend to favor gas supplies from those affiliates. Two states, Wisconsin and New Jersey, have recently established guidelines for LDC marketing affiliates. See "Wisconsin Public Service Commission Adopts Rules for Conduct of LDCs and Affiliates and Will Address Other Capacity and Supply Management Issues," Foster Report No. 2065 (February 1, 1996): 19-22; and "New Jersey BPU Adopts Guidelines for LDC Relations with Marketing Affiliates," Foster Report No. 2062 (January 4, 1996): 17-19.

${ }^{12}$ The management expert Peter Drucker refers to this outcome as "price-led costing." (See Peter F. Drucker, "The Information Executives Truly Need," Harvard Business Review [January/February 1995], 54.) 
Contrast this with a regulated world where the utility has monopoly status: unless determined to be imprudent, the utility can normally pass its actual costs to consumers. Under traditional planning practices, the utility's objective is to minimize costs subject to meeting its peak-day load and a required reserve target. ${ }^{13}$ Only implicit consideration is given to consumers' willingness to pay for utility services. In a more competitive environment the LDC would be under greater pressure to control cost and to incur costs only when they add value to services offered in the marketplace.

In sum, comprehensive retail-service unbundling would transform an LDC's planning and operation activities away from a "top down" approach and toward a "bottom up" approach. Under the latter, the LDC would start with consumer information respecting the market value of individual services to guide planning and operation decisions and the associated costs.

\section{Funding Subsidized Services}

Over the last decade, LDCs in addition to other regulated public utilities have had to broaden their corporate responsibilities as part of serving the public interest. For example, LDCs have instituted what are commonly called demand-side management (DSM) programs, arrearage programs, winter moratorium rules, economic-development programs, general rate subsidies, and low-income programs. These activities generally fall into the category of subsidies, where the benefits accruing to some customers are funded by a broader group of customers. As an outcome, customers as a group are charged higher rates to fund activities targeted at benefiting a subgroup of customers. Whether these activities should continued in a comprehensive service-unbundling environment falls beyond the scope of this report. Instead, the following section will address whether in a competitive environment LDCs will have the ability to fund

\footnotetext{
${ }^{13}$ For a discussion of LDC planning practices, see Charles Goldman et al., Primer on Gas
} Integrated Resource Planning (Berkeley, CA: Laurence Berkeley Laboratory, December 1993). 
nonmarket activities either from customers as a group or from shareholder profits. If they do, then the question becomes, How can it be done in a way that minimizes economic distortions?

For financial necessity, most nonregulated firms try to minimize their costs and to offer marketable services and products. This implies several characteristics of a firm's behavior.

First, the firm would incur costs only when they add value to the product or service being offered. Other costs, which can be classified as wastes, tend to lower a firm's profits: additional revenues would tend to fall short of additional expenses. Consequently, a firm would want to avoid those costs.

Second, a firm would attempt to maximize its revenues given the costs incurred. It would, for example, differentiate its customers on the basis of their demand preferences in order to charge nonuniform prices (that is, to price discriminate) for the same services. Consumers experience this constantly in the products and services they buy. A firm also will offer new products and services from time to time to increase (or retain) its market share and, thereby, its profits. The ability of a firm to price discriminate depends upon its market power. A firm with market power can earn above-normal profits for a sustainable period. Price discrimination represents one way for a firm to earn above-normal profits.

Third, the firm could only temporarily sell a product or service at a financial loss. When the market has a supply surplus, prices would tend to be driven down toward short-run marginal cost. At other times, prices would be driven up, never exceeding the value that consumers placed on the product or service. Selling below cost or subsidizing certain products or services is rarely seen in nonregulated markets. A firm without market power simply cannot remain in business for too long a period if subsidies are embedded in its prices.

An LDC operating in a competitive marketplace will behave more like the firms just described. Its ability to offer subsidized services, although not completely erased, becomes greatly diminished. Imposing surcharges on competitive services to pay for 
subsidies becomes especially difficult to enforce. The LDC assumes a less enviable position in the marketplace if it is required to pay for certain social activities while its competitors are not. Such payments are inevitably unsustainable, as market constraints would tend to prevent the LDC from earning a normal profit in the long term.

On the other hand, at least for the foreseeable future, the LDC will not be selling all of its services in competitive markets. For example, even in a highly developed service-unbundling environment the LDC would most likely still have market power in its distribution function. For services still subject to strict rate-of-return regulation, the LDC would have the opportunity to earn normal profits for these services as a whole. Nevertheless, the LDC could not simply attach the subsidies to regulated services and expect to earn a normal profit. Some gas customers, such as interruptible customers and customers with viable bypass opportunities, could evade these subsidies by leaving the LDC's system entirely. Because all distribution customers do not have these options, with the approval of regulators the LDC could always use its market power to extract funds from core customers to pay for subsidies. ${ }^{14}$ Even here the LDC has limitations as other alternatives (for example, electricity, energy conservation) become more attractive as distribution charges escalate to pay for subsidies.

Another funding source for subsidies can originate from the LDC's shareholders. If, for example, a commission allows PBR, the LDC would have the opportunity to earn above-normal profits. These profits could arise from the provision of new and different services, cost reductions, and the execution of flexible and market-based pricing. The LDC could reallocate a portion of these profits to funding the subsidies. In this instance, the regulator could set a performance target for specified social objectives (for example, 10 percent or less service cut-off rate for low-income households), execute PBR along with competitive-pricing flexibility, and observe after-the-fact the LDC's

\footnotetext{
${ }^{14}$ The same argument, as applied to electric utilities, is made in Robert J. Graniere, Post-Reform Continuation of Social Goals (Columbus, OH: The National Regulatory Research Institute, January 1996).
} 
performance. If the LDC fails to meet the target, the commission could impose a penalty. ${ }^{15}$

The major advantage of this approach over the straight surcharge method is that discretion is left to the LDC on how it wants to satisfy the specified social-objective target. By giving the LDC more degrees of freedom, the target is likely to be reached at a lower cost to the LDC and to gas customers as a whole. The outcome may be similar to the previous outcome - namely, price-inelastic customers funding the subsidy. It is likely, however, that the LDC would search out cost-reducing opportunities that would partially pay for the subsidies. Under a PBR plan, the LDC would have the incentive to do just that.

In sum, the accelerated competition induced by service unbundling would make it more difficult for commissions or legislatures to require LDCs to undertake nonmarket social activities. But as long as the LDC has the opportunity to earn above-normal profits for some of its services, or from a certain group of its customers, funding sources for subsidies can always be found.

\section{Comparability Conditions for Unbundled Residential Access}

In order for a policy on unbundled residential access to function successfully, all merchants must have equal opportunity to the essential facilities and confront the same rules which permit, but do not require, similar decisions. It is far less critical what the specific rules are than that the rules are applied equally. It is also far less critical that all services are unbundled than that the services not unbundled are tied to the distribution function as opposed to the merchant.

${ }^{15} \mathrm{~A}$ similar approach has been proposed for local exchange companies (LECs). The proposal, called "the minimum subscribership plan," would allow an LEC more pricing flexibility and, at the same time, provide it with incentives to maintain the social goal of universal service. See Larry Blank, "Balancing Seemingly Conflicting Goals through a Minimum Subscribership Plan: Economic Efficiency and the Risks Borne by Regulators," presented at the 27th Annual Conference of the Institute of Public Utilities at Michigan State University, Williamsburg, Virginia, December 12, 1995. 
At the same time, the efficiency gains (discussed in a later section) resulting from unbundled residential access is enhanced with greater breadth in the number of facilities and services unbundled and with more proactive rules that foster a contestable market for the merchant service.

The state regulator will want to focus on establishing a level playing field in which there is customer choice among merchants who operate under comparable rules and opportunities. Salient factors are listed in Table 7-2. In this chapter, the discussion of comparability is broken into four parts, namely, (1) issues surrounding essential facilities, (2) the regulation and pricing of gas flows, (3) the evaluation of merchants, and (4) ethics/conduct codes for merchants.

\section{Comparable Treatment of Essential Facilities}

All third-party merchants initially must be provided access to essential facilities which are necessary to provide delivered natural gas service. At the outset, essential facilities associated with natural gas procurement refer to (1) pipeline capacity or offsystem storage which is under contract to the distributor or (2) storage and supplemental peaking supplies provided by the distributor. At the same time, all merchants must have the right to refuse the pro rata offer to acquire their own contractual entitlement to these facilities. State regulators can incorporate these provisions in their residential unbundling programs. This issue hinges upon the fact that nearly all firm interstate pipeline and storage capacity to serve residential customers is currently under contract to the distributor and, given embedded cost-ofservice ratemaking, the prices for these services do not reflect market values (some may be too high, others too low). Local facilities owned by the distributor may also carry rates that differ from their market value. Thus, in some regions, third-party merchants may not be able to provide comparable service without access to these facilities on the same terms as the current distributor; in other regions the third-party merchants may not be able to identify new efficiencies in procurement without contracting from a different mix of supply and capacity providers. 
TABLE 7-2

COMPARABILITY NEEDED FOR RESIDENTIAL SERVICE UNBUNDLING

- All merchants have access to all essential facilities

- Distributor treats all merchants equally in regulating gas flows

- all customers pay same annual access fee

- each procurement service pays same monthly aggregation charge

- All merchants are evaluated on their efficiency as merchant, not tied linkages to monopolized components of delivered gas

- utility divests its merchant service, or

- affiliate entity rules apply to utility's merchant service

- Code of Ethics/Conduct for all merchants (with regulatory oversight)

- merchants should truthfully represent their service to customers

- merchants held accountable for potential costs

- consumers can switch among merchants with certain minimum notification requirements

Source: Authors' construct. 


\section{Soundness of the Merchants}

Merchants should not misrepresent or mislead their service offerings. Merchants should ensure that no loses will be shifted to other customers because of their inability to perform as claimed. Clearly, the distributor should not be liable for the costs incurred. Customers knowingly selecting merchants who truthfully revealed the risks should be liable for any unanticipated outcome.

Third-party merchants that provide unbundled residential service require at the outset equal access to pipeline transmission capacity and storage capacity. In regions where pipeline capacity is constrained and under contract to the distributors, third-party merchants require the distributor to release capacity, which it contracted for to serve these residential customers, to the third-party merchant to commence service. Probably, there is little difficulty with this conveyance. Further, this transfer reduces any stranded costs problem to the distributor or pipeline. ${ }^{16}$ This requires state regulators to mandate that the utility releases capacity to the residential customer's third-party merchant. On the other hand, in regions that experience surplus pipeline and storage capacity and when multiple pipelines exist, third-party merchants may not want entitlement to the capacity contracts that the distributor was using to serve these residential customers. This situation relieves the state regulator from mandating reassignment of the distributor-pipeline contracts, but raises the issue of stranded costs and their allocation.

In some regions, numerous parties provide storage. The FERC has, in fact, granted certificates to several storage facilities with deregulated terms because a sufficient level of competition exists. Some new storage fields are being developed which provide more economical injection and withdrawal terms. Even in light of these developments, the state regulator must actively establish rules permitting reassignment of entitlements to local and purchased storage among alternative merchants. These

16 The difficulty may arise when the third-party merchant seeks less than a one-to-one reassignment of capacity because it may perceive a more economical option to meet residential load.

THE NATIONAL REgULATORY RESEARCH INSTITUTE- 84 
entitlements may permit the distributor's merchant to possess a comparative advantage and to capture rents should the merchant function become unregulated. Without such rules, the distributor-affiliated merchant could have an advantage not based upon efficiency.

How the FERC addresses pipeline comparability between a pipeline's merchant and other entities relates to how a state commission may address the distributor's merchant services and other entities within the city gate. The FERC resolution, however, does not sufficiently address the issue of comparability among merchants for firm burner-tip service behind the distributor's city gate. Most merchants for unbundled residential service will use firm transmission capacity, some of which will be contracted directly, purchased on the secondary market, held by the producer and, at least initially, obtained from the utility's capacity entitlement. With unbundled residential access, the third-party merchant can only compete if the state regulator ensures that these merchants can initially gain access on the same terms as that possessed by the utility's merchant. Because the third-party merchant is a competitor, this access to capacity whether transmission or storage cannot be assumed to arise through private negotiations with the utility.

\section{Comparable Treatment in Regulating and Pricing Gas Flows}

The distributor must have control over regulating gas flows to maintain the integrity of its system. This control over gas flows does not prevent unbundling. Two dimensions are important - operational issues associated with the physical gas flow and the pricing of this flow.

\section{Distributor's Rules for Nominations, Balancing. Penalties. The distributor} must have control of its system integrity. The distributor should establish rules for nominations, scheduling, and balancing such that operation is efficient. Penalties should be established not only to compensate for diminishing efficiency but also to discourage these actions in the future; thus, establishing penalties that exceed costs is 
valid. On the other hand, excessively high penalties can act as a barrier to entry or can discourage economical use of natural gas. Wise regulatory oversight is required.

Even when the utility has separated its distribution function from its merchant function and penalties are applicable to all merchants, penalties paid by the utility's affiliate merchant become revenue to the parent company. When the distributor's marketing affiliate incurs these costs, a simple transfer occurs. When the third-party merchant pays them, the parent company receives a monetary gain. Hence, from a public-interest perspective, the distributor may have an incentive to establish penalties higher than what is optimum. It is insufficient to simply say that whatever standard the distributor establishes, the rules should apply equally to all merchants, including its own merchant arm. As another point, all merchants should be permitted to treat their customers as an aggregated pool; and merchants should be able to trade among themselves such as to maintain nominations, stay within balances, and minimize penalties.

2. Distributor's Rules for Customer Hook-Ups. Whatever customer hook-up policy (who can be refused service for whatever reason) is currently in place can continue to be applicable to the new third-party merchant and the distributor's merchant affiliate. The current shut-off policy and bad debt-collection policy can continue; all bad debts can be recovered through the distributor's distribution charge. Should the thirdparty merchant deliver through its own grid off of an interstate pipeline, this service should be unregulated with the above policy not applicable.

3. Distributor's Rules for Load Balancing. The distributor may currently employ storage to shave its peak-period demand for transmission capacity and to manage shifting hourly loads within any day. Load balancing appears legitimately related to the distribution function, while shaving peak-period demand is most related to the merchant function. This split requires a regulator's determination.

If the distributor's storage is essential for both functions, third-party merchants must have proportional rights to local storage for shaving peak demand. The demand for the distributor's peak shaving may be more related to the low regulated price than to 
the unavailability of other storage alternatives. The natural gas industry is quite dynamic; the best way to meet the demands of low load-factor customers may be other storage areas, new storage facilities that permit faster injection/withdrawals, exchanges, backhauls, and market hubs that provide new pipeline linkages. On the other hand, local storage, as well as supplemental supplies, may be essential facilities to warrant some state regulatory policy. These facilities may also be too costly, an albatross which may become a stranded cost that requires a regulatory response.

If local storage is both essential and economical, regulators allowing unbundled residential access have two choices. First and easiest, the regulator leaves storage as part of an LDC's bundled distribution package to which all merchants have proportional rights. The third-party merchant delivers its supplies to the distributor in much the same manner as the distributor's merchant operation has done in the past, and presumably, the merchant affiliate will do in the future. This has been the pattern in Canadian provincial schemes. Alternatively, the customers' merchant can be given proportional rights and be allowed to determine its own options constrained only by limits on its own use of the distributor's storage. As a second alternative, the state regulator can require the divesture of local storage (as well as other supplemental supply facilities). Revenues earned from the divestiture would be credited to current distribution customers. Then, the state regulator would require the new owner of the storage facility to operate with open access rules.

\section{Distributor's Pricing of Merchant Service. Often transportation customers} have been assessed a transportation charge that embodies a margin (retail price minus city-gate price less the cost of the gas supply department) equivalent to the margin earned under bundled sales service, plus additional charges for administration of transportation accounts and a metering charge for more precise measurement of use. This accounting procedure presumes that the distributor's gas under bundled service flows first through the pipe, and costs arise only in keeping track of other gas flows. For full comparability, the gas flows of all merchants for firm service must have equal footing. All firm gas, irrespective of who the merchant is, has won its pro rata place in 
the queue for delivery. Additionally, all customers irrespective of their merchant should experience a similar access fee in their bill. The customer who continues to take service from the distributor's affiliate merchant would also pay this same charge.

The distributor treats all customers of its bundled sales service as an aggregated pool for whom the usage is projected and measured on a monthly basis. The same guidelines appear appropriate for third-party merchants serving these residential customers. These customers who take a particular service from a particular merchant are treated as one aggregated pool. Nominations, balances, and penalties for imbalances apply to the entire pool. Further, because the distributor gains market information on all customers and all merchants, the distributor gains a comparative advantage if the same personnel both regulate gas flows and provide merchant service.

5. Local-Peaking Supplies. For many distributors, the current provision of leastcost service to residential customers hinges upon the distributors possessing local propane and liquefied natural gas (LNG) peaking facilities. For a third-party merchant to provide comparable merchant service, access to these facilities may be critical. Two alternatives include granting proportional access rules and spinning these facilities off as stand-alone entities. The selling price arguably would be at market levels. Future prices would reflect marginal value.

\section{Eligibility of Customers and Merchants}

An often-heard caution of an unbundled residential access policy is whether residential customers have sufficient information to make intelligent choices, and whether eligibility should not be limited given the absence of these customers' ability to use alternative fuels in the event of a supply disruption. The question arises as to whether the state regulator should establish a high hurdle on a third-party merchant who serves residential customers. 


\section{Customer Eligibility}

Reliability concerns do not necessitate that an alternative fuel is available; gas merchant or gas supply portfolios can provide this reliability. Reliability should be gained through the marketplace, not through some subsidy. The industry is quickly learning that the price mechanism can play an allocating role in providing adequate security to customers. Reliability concerns should therefore not be an obstacle to acquiring unbundled service.

Questions revolve around the knowledge of the residential customer to evaluate alternative supply portfolios. We do observe consumer preferences for different portfolios. For example, consumers are able to differentiate among different bond and equity portfolios, and different demand deposits. The different portfolios require distinction between current and future rewards and differentiate risks.

Concerning the availability of competitors, residential customers are often viewed as too costly to serve relative to the profit potential on the merchant service. Some industry observers believe there will not be sufficient competition among merchants to serve those residential customers with low gas usage. Both confusion and misunderstanding surround these concerns.

The confusion here relates to the perception that (1) each customer must have a meter that can be read daily, (2) individual billing costs will be associated with the thirdparty merchant but not the traditional merchant, (3) a relatively large per-customer access fee will be charged by the distributor, and (4) the high costs associated with serving customers with low load factors will be associated uniquely with the third-party merchant.

First, the usage of a firm residential customer can be statistically estimated based upon past patterns and, hence, be billed as accurately whether delivery originates from a third-party merchant or the utility. Knowing the usage of residential customers who take firm service is easier and cheaper than, for example, knowing the usage of an industrial customer who takes interruptible service. 
Second, the current cost to bill the residential customer is relatively high given low usage. This cost does not vanish, but the additional cost imposed upon the utility for city-gate delivery is negligible. The only significant cost is keeping track of aggregated flows in and out on a daily and monthly basis. Yet, these costs are again minor when divided by the total number of residential customers in its aggregator's pool. Thus, there should be no new large fee assigned to residential customers under an unbundled access program.

Third, low load factors are more costly to contract for irrespective of whether services are unbundled or not. The availability of competition among merchants in the provision of this contracting may provide greater opportunity to lower these costs, rather than to drive them higher. Customers will not select this alternative if higher costs result.

\section{Merchant Eligibility}

If private contracts are not enforceable or if the transaction costs are too high for some entities, then an argument can be made for regulatory intervention. One regulatory action would be to require all merchants to post a bond such that customers would be protected from malfeasant behavior. The regulator must exercise concern that the magnitude of the bonding does not act as a barrier to entry. As one idea, basing the size of the bond on the amount of natural gas being delivered to the customers being served may alleviate this concern. At the same time, the merchant service is likely to have a number of competing merchants, each of whom seeks new customers from others who are themselves not malfeasant. Because contracts will turn over frequently, for a merchant to maintain its customer base it must be responsible and cost effective. 


\section{The Obligation To Serve}

State public utility laws have mandated that local gas distributors accept an "obligation to serve" as part of their obtaining a certificate of public convenience and necessity. This obligation stems from the distributor's natural monopoly position in the delivery of natural gas. When this legislation was enacted, and for seventy years or so afterwards, delivered natural gas was one packaged product. Within the past decade, this characterization of delivered natural gas has been fundamentally altered by both technological and federal regulatory changes. ${ }^{17}$ Regulators of twenty-years ago, let alone the original legislators, would not recognize today's vibrant natural gas industry with market hubs, independent marketers, third-party providers of storage, electronic bulletin boards (EBBs) providing instantaneous information, futures markets, diverse contract terms, and distributors with multiple pipeline interconnections. Currently, some components that comprise delivered natural gas are still characterized as a natural monopoly; others are best characterized as fully competitive.

The obligation to serve was imposed as a restraint on monopoly power. Because monopoly power no longer exists over the contracting and sale of gas supplies to most consumers of natural gas, both regulators and legislators may want to redefine the distributor's obligation to serve. In those functions for which the distributor still has a natural-monopoly position, such as provision of the grid of pipes, compressors, meters, and the control of gas flows through these pipes, the obligation to serve should remain. In those functions for which the distributor is only one of many who could perform the service, the obligation to serve should be removed from the distributor. Alternatively stated, for any activity under which efficiency-inducing competition can occur, state policy could remove the distributor as a regulated supplier of that activity.

\footnotetext{
${ }^{17}$ Further, customers have experienced lower-priced service when purchasing unbundled service; this refutes any validity to the natural monopoly argument that only one firm should exist such that economies of scale or economies of scope can be realized. Yet, as open access evolves, competition among merchants may reveal economies of scale that are achieved by serving national markets.
} 
There are two approaches that state regulators can initiate to gain this deobligation. First, state policy can simply announce a new regulatory framework at some point in the future, and allow the distributor and other parties time to reposition themselves. Second, state policy may allow customers to exercise choice. Thus, customers would voluntarily determine the speed and timing of this transition. The second policy, however, may disadvantage the distributor as a merchant versus its new competitors since it would still incur costs to satisfy the service obligation of those customers who choose to remain. Further, this policy may create artificial distinctions and restrictions that limit the choices available to some customer classes.

To better clarify the dimensions to eliminating the current obligation to serve, four frequently heard statements are identified:

1. The obligation to serve is still needed for customers making small use of natural gas. Although in agreement with the views of many regulators, this assertion has little merit. ${ }^{18}$

2. The obligation to serve is still needed for customers with a bad credit record. This is a social issue that should be addressed separately. ${ }^{19}$

3. The obligation to serve is still needed so that customers wishing to return to the utility can do so. This begs the question, Why does the customer seek to return to the utility if the utility is selling natural gas as a market-priced service? If market-priced, there will always be others also providing the same service. Mandating an obligation to serve is not necessary.

4. The obligation to serve is still needed for emergencies. This has some validity. In the current natural gas industry, price allocates natural gas among alternative users and affects the amount of natural gas produced and taken from storage. No-notice service can be priced and provided by more

\footnotetext{
${ }^{18}$ See the discussion in this chapter on customer eligibility.

${ }^{19}$ See the discussion in this chapter on subsidized services.
} 
firms than just the local gas distributor. The provision of no-notice service is similar to load balancing, namely, the distributor as the controller of gas flow is a natural entity to provide these services, but others may also be capable.

The argument here is that the short-term control of gas flows may require some balancing and no-notice service by the distributor. The customer should pay the required price plus some penalty. The regulator must be concerned that the reason other firms have not stepped in may be related to (1) the specification of an ill-defined service against which they would compete, (2) the fear that they would become regulated, and (3) the nonprovision of timely information needed to enter the marketplace.

The regulator should not eliminate the distributor's obligation to provide backup service for short periods. This service should be priced at cost plus a penalty. Thus, any event in which wells freeze, supply is not forthcoming, or a financially distressed merchant is no longer in business becomes mitigated. The utility must maintain the integrity of its system. But the utility must also provide timely information such that customers and their agents can voluntarily seek alternatives. Doing so would lessen the importance of this "supply-of-last-resort" obligation.

\section{Allocation of Stranded Costs}

Unbundled residential access permits customers to select alternative merchants. These merchants, unless constrained by the regulator, may contract from different producers, storage facilities and pipelines, or from the same producers, storage facilities and pipelines on different terms, or from third parties who hold entitlement to commodity, storage, or transmission capacity. The distributor may also have investments (rate-based assets) in local storage or peak-day supplement facilities that may become less utilized. Thus, unbundled residential service poses risks to the distributor: its contracts with producers, storage facilities, and pipelines for service and 
its own local supplemental supplies may no longer be commercially viable. ${ }^{20}$ The failure to recover these contractual costs or, in the case of local services, for a distributor to obtain its projected revenues creates stranded costs for which the distributor will seek recovery from customers through the regulatory process.

A regulatory policy on unbundling residential service should concomitantly encompass a policy statement on the treatment of stranded costs, how these stranded costs are allocated, and whether stranded costs will be permitted to nullify customer choice. The magnitude of stranded costs can be minimized by the following three conditions:

1. The distributor's portfolio of gas commodity contracts and purchased capacity entitlements to multiple pipelines and storage facilities and local supplemental supplies represents a best-cost service. ${ }^{21}$

2. The distributor's portfolio of contracts has market-out termination and renegotiation provisions. These provisions can allow the distributor to quickly exit from the merchant service if warranted by market conditions.

3. At the same time that unbundling occurs, the distributor's merchant affiliate is permitted to repackage its portfolios in a way that matches the diverse preferences of its customers.

These dimensions to stranded costs will be discussed individually.

\section{Best-Cost Portfolio}

The FERC's open access rulemakings (Orders 436, 500,636) have limited the distributor's freedom to reposition its purchased capacity portfolios in light of customers exiting to transportation, vastly different rate designs, and new emerging market opportunities. Thus, in the mid-1990s some LDCs are just now altering capacity

\footnotetext{
${ }^{20}$ For pipelines, unbundling may induce LDCs to not resubscribe to long-term capacity as existing contracts expire.

${ }^{21}$ The extent to which the contract is commercially impractical may be lessened by a secondary market in which the distributor can resell the basic entitlement.
} 
portfolios that for years have been badly out of sync; these portfolios were by no means best cost. ${ }^{22}$ Any upstart merchant could provide equally superior service at lower cost. For most distributors, however, many of their contracts with interstate pipeline supplies have run their term and new contracts are more in balance. Thus, the importance of stranded costs under unbundled residential service has diminished.

\section{Policies To Minimize Stranded Costs}

In general, it is here argued that the state regulator should seek policies that foster greater efficiencies in retail gas markets even if more stranded costs arise. The state regulator's directive would then be on the allocation of these stranded costs such that greater efficiencies are not foreclosed while minimizing equity impacts to customers and the utility's shareholders. Alternatively, the state regulator could mandate that the third-party merchant subsume the contracts for pipeline capacity that the distributor holds. In this case, no stranded costs arise, but the degree of foregone cost efficiencies are not revealed. Some may argue that in the case where customers swing back to the distributor as their merchant, the third-party merchant must hand back the same amount of transmission capacity as was released. Thus, optimal service and reliability have been maintained. Of course, in this scenario, optimal service has never freely been determined.

When the distributor is linked to only one pipeline and the pipeline is capacity constrained (that is, demand for capacity exceeds supply), the prior scenario is necessary for comparability of service. Plainly, the release of some transmission capacity is essential, but this need not be a one-to-one entitlement to what the distributor had obtained. Unbundled residential access in this situation would likely produce fewer savings. On the other hand, stranded costs would be smaller. to the LDC.

22 "Best cost" takes into account purchased price, the reliability of service, and the incremental risk 
Unbundled residential access programs, even those in which the merchant function becomes deregulated, should not be prevented simply because the region is served by one pipeline or a capacity bottleneck exists.

\section{Exit Costs}

Stranded costs can be assigned to those customers who directly benefit. These customers would pay an exit fee to switch from the distributor's merchant function. Yet, raising the costs of exit lowers the number of new efficiencies that will become identified. Presumably, the state regulator would value having a greater number of third-party merchants to best meet customers' preferences. This argument is inconsistent with the imposition of exit fees. Further, the inefficient merchant often adjusts because of competition and its remaining customers often benefit by the new portfolio. Consumers can experience a win-win environment, particularly over time.

If stranded costs are not assigned to those customers who "caused" them or to those customers experiencing benefits, who should absorb those costs? First, it is difficult to identify those who caused them and to limit those in the category of who benefited. If prior regulation encouraged the LDC to have such contracts, then how can the LDC be held accountable now? The solution may lie with the principle of spreading the costs as widely and evenly as possible. Because for the vast majority of customers the distributor grid is an essential facility, these stranded costs can be recovered through an add-on to all customers' distribution charge to both firm and interruptible transportation service.

\section{Distributor Error}

The distributor's portfolio has frequently been subject to least-cost planning dockets before state commissions and, to a lesser extent, to management audits. The distributor's portfolio reflects prior commission rulings on what constitutes prudent contracting. From this it follows that stranded costs should not be absorbed completely by the shareholders of the distributors. This is particularly the case where it is not the fault of the distributor that its portfolio is ill-suited to particular niches of customers. In 
this case, stranded costs would appear to be mitigated by permitting the distributor to repackage its total portfolio for particular market niches. If the regulator has made the entire market comparably accessible for entry by all merchants, this policy to reduce stranded costs appears appropriate.

\section{Marketers/Brokers and Unregulated Utility Affiliates}

Unbundling residential service requires a sufficient number of merchants or the potential entry of merchants to motivate existing merchants (even if this is only one) to offer the best menu of services at the best price. Without this workably competitive environment, greater deference to market forces cannot be relied upon to foster just and reasonable terms of service. The natural gas market offers many alternatives to the contracting and pricing of delivered natural gas. The merchant for the residential customer would need to constantly exploit these alternatives. The regulator would no longer be making "prudence" determinations on the multitude of individual decisions required. As mentioned before, instead the regulator's effort should foster an environment in which entry and exit ${ }^{23}$ of merchants can occur with ease, while ensuring that residential customers are able to make informed choices on the marketer/broker and the quality of service.

Customers must be able to experience choice in who is their merchant and in the portfolio of terms associated with delivered natural gas. Customers should confront, among other things, alternative prices and alternative price-risk tradeoffs. Many customers place considerable trust in their current distributor's service; this trust should be continued, but only in an environment in which the distributor's affiliate demonstrates

${ }^{23}$ The regulator who raises the cost of a merchant exiting for the provision-delivered natural gas, for example by indemnifying its customers from any costs resulting from the merchant's decisions, raises the cost of entry. By acting as a barrier to entry, existing merchants could earn excessive returns or provide portfolios with higher costs than what would otherwise exist. This highlights the problem posed how to ensure the benefits of competition while, at the same time, avoiding any undue harm. 
its own superiority as a merchant. Thus, an integral part of residential unbundling is the separation of the distributor's merchant function into its own stand-alone, operationally separate business unit.

\section{Affiliate Entity Rules}

Unbundling residential services forces an examination of the current activities of the local gas distributor. Further, experience suggests that the regulator's ability to establish comparability of service between those merchants tied to other services and third-party merchants is costly and difficult without some separation. Judge Green's unbundling of telephone services entailed the divesture into separate units; the FERC's unbundling of natural gas interstate pipelines entailed the formation of affiliated entities. State commissions face these same issues with regard to their gas distributors. There is a comfort factor to both the regulator and to a number of consumers in seeking affiliate relationships rather than total divesture.

The unbundling history at the FERC may be instructive. The FERC initially permitted the pipeline to continue as both transporter and merchant. The FERC issued Order 497 , which set forth affiliated entity rules such that pipelines were less able to transfer their monopoly power over transmission to their marketing affiliate via (1) restricted access or (2) distorted prices. This was followed by Order 636, which required pipelines to exit the merchant function but permitted these activities to be transferred to an unregulated marketing affiliate. Order 636 again relied upon principles in Order 497, which established arms-length transactions, separate staff, separate location and facilities; but Order 636 also set forth stiffer reporting requirements. For example, discounts from a pipeline to its marketing affiliate must be immediately posted on the pipeline's EBB, whereas this was not required between the pipeline and thirdparty merchants. 


\section{Necessary Rules For Efficient Service}

Wise regulatory policy should be directed toward creating a level playing field for the merchants servicing residential customers. It should also create an institutional setting such that this competition generates the greatest benefits and the most efficient levels of service. Unbundled service cannot be efficient without comparability, which was discussed earlier, but comparability is not sufficient: efficiency depends also upon several additional elements. These are shown in Table 7-3.

\section{Extent of Unbundling and Rules on Contracting}

Customers should be able to choose among merchants who not only procure the commodity but also arrange transmission capacity, storage facilities, local peaking service, and perhaps the provision of back-up supplies and load balancing. The degree of efficiency improvement increases with the greater number of services available for the merchants to arrange.

State regulators must also determine if the market for each service is contestable. This determination is not based simply on the number of merchants serving residential customers but whether entry would occur that would discipline and drive prices to competitive levels. Contestability hinges on the ease of potential entry and exit for each of these services, not upon the number of alternative merchants currently providing these services. For those services which are contestable, the state regulator may want to defer to the market for the determination of just and reasonable rates and the variety of portfolios offered. ${ }^{24}$ Once the market is judged contestable,

${ }^{24}$ State regulators may have greater ability to defer to market prices when the market is deemed more competitive than often alleged. For example, the Economic Regulatory Administration was charged by Congress to make just and reasonable determinations on the importation of natural gas supplies into the United States. The Energy Regulatory Administration ruled in the 1980s that the market for importing natural gas into the United States was competitive; thus, voluntary contracts for this importation must by definition meet the regulatory requirement of being just and reasonable. The courts have upheld this reasoning. 


\section{TABLE 7-3}

\section{NECESSARY RULES FOR EFFICIENT SERVICE}

- Competitive services should be unbundled.

- All merchants can contract for commodity, transmission and storage capacity in whatever manner they deem best.

- For contestable services, all merchants can charge market-based prices and provide multiple services.

- Information on gas flow balances is easily obtained.

- Information on alternative prices charged by various merchants is also easily obtained.

- Administrative fees charged for a merchant's service are minimized, fees for nominations and balances are by aggregated pool, and trading is permitted among aggregated pools to lessen imbalances.

- Penalties for imbalances do not act as an undue barrier to entry.

Source: Authors' construct.

fewer regulatory constraints can be placed upon the provision of multiple services by the distributor's affiliate merchants. Thus, the affiliated merchant need not be hamstrung by offering only one gas procurement package; rather a portfolio of packages can be offered to meet the variety of preferences of the residential consumers. 


\section{Administration Costs Minimized}

State regulatory policy should not establish conditions that would make unbundled services prohibitively expensive and preclude the entry of any third-party.

\section{Market-Based Rates for Unbundled Competitive Services}

Market-based rates will reflect the current marginal value and the cost of the service provided. These latter linkages are supposed to result in the greatest social welfare by encouraging physical and allocative efficiencies. Market-based rates are governed by privately negotiated terms and often are entirely flexible and adjust immediately to changing conditions.

\section{Charges Associated with Unbundled Services}

To minimize the barriers to entry, administrative fees should apply to all residential customers including those taking service from the merchant affiliate of the distribution utility. All customers taking the same service from the same merchant should be treated as part of one aggregated pool.

Penalties on imbalances should discipline merchant behavior and exceed cost of service, but should not exceed costs to the point that the potential for these penalties acts as a barrier to entry.

\section{Information Sharing}

Better decisions result when the cost of acquiring information is lowest. Thus, in establishing unbundled residential service state regulators should try to seek an institutional environment in which the distributor gains revenue when more efficient throughput is achieved and to which customers can more easily determine which merchant best provides the service they seek. If the state regulator establishes incentives, information sharing may result naturally, that is, without mandates by the regulator. 
Experiences of the interstate pipelines demonstrate that EBBs facilitate greater utilization of the pipeline by those who place the highest value on the natural gas. That is, greater physical and allocative efficiency has resulted from the EBBs. Extending the EBB at the distributor level may also be desirable. If the utility provides a distribution function as a stand-alone service and if the distributor's profit hinges on the throughput, the distributor has its own internal incentive to make lower-cost information available to potential users. The distributor in an unbundled service environment may seek to provide its own EBB service. Further, the utility's merchant would be one customer seeking to make use of this service.

The distributor would maintain the EBB; it would develop a format code to facilitate customer switching among merchants and the aggregation of the prior uses and projected future use.

Consumers also require ease of gaining information on likely differences in costs among alternative merchants. In most markets, currently price differentials can be observed by calling alternative suppliers and reading informational advertisements. Periodically, newspapers and other private entities constantly publish the prices and terms of alternative merchants. There is no reason to suspect that such reporting cannot occur for residential gas service, even if the state regulator shows total benign neglect. The state regulator could, without getting into regulating the merchant service, seek to have alternative prices for different portfolios of each merchant become reported to the commission and publish summary information on an annual basis. Greater access to this information may help drive the unregulated prices to competitive levels. 


\section{CHAPTER 8}

\section{GUIDING PRINCIPLES FOR CARRYING OUT RESIDENTIAL SERVICE UNBUNDLING}

The acceptability of residential service unbundling hinges largely on its compatibility with prevailing regulatory objectives. The fundamental argument in support of such unbundling is that it would expand market opportunities for all retail gas customers. In the process of achieving this outcome in a way that promotes regulatory objectives, which has both economic and political appeal, certain conditions need to be met. Unbundling per se in the absence of compatible regulatory changes can, on net, cause more harm than good.

As discussed earlier, changes in obligation-to-serve rules, pricing methods, and the regulatory ratemaking paradigm itself will be needed to assure that unbundling improves the economic performance of the retail gas sector. Guidelines for residential service unbundling require a set of principles from which policy directives can be formed. Eight major principles, consistent with the earlier chapters of this report, include:

1. The more service choices available to customers, the better off these customers are. Service unbundling allows customers to choose among different gas services and providers in a way that maximizes their welfare. As a general rule, customers prefer to have more choices in the products and services they consume. Repackaging of unbundled services should be an integral part of any policy to give customers more choices.

2. Bundled sales services should continue as an option (for example, a "recourse senvice") for residential customers. Some of these customers may believe that cost savings from switching gas supplies are minimal and that the highly reliable service they demand can only be provided by bundled sales service. Bundled service represents one alternative that some 
customers, for different reasons, may prefer. At least during the initial years of residential service unbundling, customers should have the right to stay with bundled sales service if that is what they wish.

3. Any party providing services shall be highly dependable. Since the cost of interruptible service to most residential customers is extremely high, thirdparty gas providers should demonstrate their ability and willingness to serve those customers on demand. Some residential customers may be willing to accept less reliable service, in which case they should be able to choose among different service-reliability options. For those customers opting for less reliable service, the market would allow them to pay a lower price for gas service.

4. The $L D C$ should be compensated for any costs imposed upon it by a third party (for example, an aggregator or marketer). Additional costs and risks forced upon the LDC should be paid for by those directly benefiting from service unbundling. Externalizing risks, for example, represents a form of cost shifting that conveys a false signal to customers assessing the benefits and costs of unbundled services.

5. The LDCs' obligation to serve as the supplier of last resort should be compatible with the compensation received for the provision of these services. If the LDC is required to provide backup and other "insurance" services to assure customers high reliability, it should receive compensation. Backup service or any service made available by the LDC should be compensatory in the sense that, at a minimum, revenues should cover costs.

6. The $L D C$ should be required to unbundle as many services as deemed consistent with improving economic efficiency. In theory, service unbundling can be carried out excessively. It is likely, however, that many individual services beyond the city gate can be efficiently sold and priced separately. 
7. The LDC and competing gas service providers should have equal opportunity to sell in the retail market. When equal opportunities fail to exist, it becomes difficult to ascertain whether those supplying gas services are actually the lowest-cost providers. As a basic requirement for efficient markets, all suppliers should be subject to the same rules.

8. Regulatory rules should correspond to the degree of competition induced by service unbundling. As markets become more competitive, regulators should lighten their control over a firm's prices. Tight regulation of services subject to competition can jeopardize the regulated firm's market position as well as the benefits to customers.

These eight principles should help to maximize the benefits of service unbundling to both customers and society at large. They mostly accomplish this by endorsing the general premise that customers benefit when they have more service options and society gains when risks become internalized to the decisionmaking party. Further, the principles presume that most residential customers will continue to demand highly reliable service, irrespective of the service provider.

Lying behind some of the principles is the need for the proverbial "level playing field." From an economic perspective, this condition will guarantee that those service providers with the lowest costs will win out over their competitors. Executing this efficient outcome requires the following state of affairs: (1) sufficient pricing flexibility for all potential gas-service providers, (2) availability of both bundled and unbundled services, (3) market- accommodating regulatory rules, (4) no government-induced costs (for example, low-income assistance) unevenly imposed on service providers, (5) nondiscriminatory access to essential facilities by all service providers, (6) the elimination of cross-subsidies or cost-shifting that would favorably position the regulated entity in relation to its competitors, and (7) compensatory pricing of services provided by the LDC for the benefit of unbundling customers or their agents.

In competing with each other, the different service providers would fight to make sure that the playing field is tilted in their favor. Marketers, for example, would want to 
be charged the lowest price possible for complementary services provided by the LDC and to have favorable access terms to essential facilities. Consumers would want choice and lower prices, which means that they would prefer a world where unbundled services and bundled services coexist. The LDC would want the opportunity to compete, to earn higher profits in competitive or quasi-competitive markets, and to be relieved of what they consider to be burdensome regulatory obligations (for example, social activities and traditional service obligations). Finally, regulators would want an all-win outcome where no stakeholder loses and to be perceived as advocates of procompetition in light of current political and market pressures.

Overall, three general conditions are required for a "level playing field" or, to put it similarly, a competitive environment that guarantees economic efficiency. They are: consumer choice of different service providers, no regulatory price or entry barriers, and nondiscriminatory access to essential facilities. When these conditions exist, in most situations competition is both robust and socially desirable. 


\section{CHAPTER 9}

\section{CONCLUDING COMMENTS}

When all is said and done, the fundamental question for regulators comes down to whether residential service unbundling represents good public policy. If state PUCs believe that all retail gas consumers should directly benefit from competition by having market choices, then residential service unbundling will be viewed as an acceptable policy. Service unbundling allows consumers the ability to search out the best deals and select among different service providers so that they can maximize their economic well being. As shown with the experiences in other, previously heavily monopolistic industries, service unbundling in addition to reflecting the symptoms of competitive forces is a driving force for accelerating competition in an industry.

Few observers would contest the benefits from service unbundling that have already accrued in the natural gas industry, both in the pipeline sector and for large retail consumers. A greater number would question, however, whether service unbundling for small retail consumers would be good public policy as well. After all, a common view is that small consumers would really not want to make choices because of high transaction costs, and would demand highly reliable service that only bundled sales service could provide. This report doubts the validity of these perceptions: load aggregation by marketers should significantly reduce transaction costs for individual consumers, and the combination of contracts and regulation should maintain reliable service to those residential consumers who take unbundled service.

Compared to large customers, it is likely that more small customers would want to retain bundled sales service. From a public-policy perspective, this implies that residential customers should have the right to choose between unbundled and bundled service. Forcing all residential customers to take unbundled service would restrict their choices, with some customers expected to be worse off as a result. 
One major issue currently before state PUCs is how small gas customers can benefit more from competition in the natural gas industry. In some states, the discussion has shifted from how to protect small customers to how to give these customers the same market opportunities as large customers. In other states, preventing small customers from paying higher rates because of competition in largecustomer markets has become the dominant policy. For these states, performancebased regulation and allocation of revenue credits earned in noncore markets to core markets represent possible ways to protect small gas customers. If a commission wants to go beyond "protecting small customers," service unbundling seems to be the logical and most meaningful alternative.

Expanding the scope of service unbundling should accelerate competitive pressures in the retail gas sector. If done correctly, residential service unbundling should improve economic efficiency in the natural gas industry. It will pressure both regulators and LDCs to terminate existing cross-subsidies and inefficient rate designs, encourage the entry of cost-efficient service providers, allow customers more choices of service providers, and impel LDCs to be more cost conscious and customer responsive.

For these benefits to happen, however, regulatory rules will need to change. As discussed earlier, existing rules are premised on a highly monopolistic retail gas market. Expanded service unbundling will engender strong competitive pressures to emerge in the retail gas market. Leaving existing regulatory rules in place will likely produce transitory distortions that would seriously undermine or greatly diminish the societal benefits that service unbundling can offer. This report outlines a set of general and specific guidelines that regulators can apply to mitigate these distortions, as well as to maximize the societal benefits from service unbundling. 